\title{
MPPT Based On Artificial Neural Networks (ANN) For a Photovoltaic System Under Unstable Environmental Conditions
}

Pascal Kuate Nkounhawa ( $\square$ nkounhawa@gmail.com )

University of Dschang: Universite de Dschang

\section{Dieunedort Ndapeu}

University of Dschang: Universite de Dschang

Bienvenu Kenmeugne

University of Yaounde I: Universite de Yaounde I

\section{Research Article}

Keywords: Photovoltaic system, Modeling, MPPT controller, Artificial neural networks (ANN), Converter, Unstable environmental conditions, Operating point

Posted Date: December 22nd, 2021

DOI: https://doi.org/10.21203/rs.3.rs-1067676/v1

License: (c) (i) This work is licensed under a Creative Commons Attribution 4.0 International License. Read Full License 


\section{Abstract}

In this article, an artificial neural networks (ANN) based maximum power point tracking controller (MPPT) was developed to improve the performance of the FL-M-160W solar panel under unstable environmental conditions. To develop and configure the neural controller, a database resulting from experimental tests was built for the training of the proposed model. Then the model was tested and validated under the Matlab / Simulink environment. The optimum voltage obtained at the output of the neural controller is compared to the voltage of the photovoltaic generator and the error is used to modify the duty cycle of the DC-DC boost converter. It is shown after simulations that unlike conventional controllers which are very slow, the neural MPPT controller offers more stable, more accurate output characteristics with very low response time and very low oscillations around the operating point both in transient and steady state, even under varying environmental conditions.

\section{Introduction}

Fossil fuels represent more than $81 \%$ of the energy consumed in the world. These energies generally used in the field of transport, production of electricity and heat as well as for industries are at the origin of the degradation of human survival conditions through the phenomenon of pollution and degradation of the climate that they generate [1,2]. With the increasing evolution of the population, the International Energy Agency (IEA) estimates in its 2007 reports a world energy demand of about $60 \%$ between 2000 and 2030 with an increase of $19 \%$ for the 2040 horizon according to the reports published in 2020 . However, subSaharan Africa indeed has the lowest rate of access to electricity in the world, with an average rate of $32 \%$ according to the report of the African Development Bank published in 2010. To increase the rate of people having access to electricity and reduce the rate of degradation of phenomena generated by the consumption of fossil fuels, renewable energies are positioned as alternative energy sources to ensure energy security of the planet $[3,4]$. These energies constitute energies with inexhaustible flows, generating little or no waste or polluting emissions. To take advantage of the strong solar potential that prevails in the sub-Saharan region, photovoltaic solar energy appears as an interesting solution [5].

In recent years, photovoltaic solar energy has experienced intense development in Cameroon because in addition to the objective of reduce pollution produced during the process of transformation of fossil fuels into electricity, Cameroon also aspires to move closer to its energy independence. Today, we are witnessing the disappearance of traditional electric lamps in favor of solar lamps for the lighting of public spaces as well as an interest of people for the electricity supply of homes in photovoltaic (PV) energy.

Although these PV systems are now installed, they present many malfunctions due mostly to the inadequacy of the MPP tracking algorithms of the adaptation stage on the one hand and sudden variations in environmental conditions. There is a problematic of non-mastery of maximum power point technology (MPP). To extract at any time and whatever the weather conditions and / or state of the load supplied, the maximum power at the output of the PV panel, the voltage at the terminals of the panel 
must continuously been regulated to its optimum value through the adaptation stage. This operation is called the maximum power point tracking (MPPT).

Many algorithms have been used to track the MPP in a PV generator $[6,7,8]$. Although these algorithms have proved their worth, the fact remains that they still have limits in terms of stability, response times and significant presence of oscillations $[9,10]$, especially for sub-Saharan conditions where environmental conditions are very changeable and have a considerable impact on the efficiency of the solar generator. Since the I-V and P-V characteristic of the PV generator is strongly nonlinear, it has been proven that the neural network gives excellent prediction accuracy for the control of a nonlinear system. Unlike conventional controllers, neural MPPT control has proven to be a very effective solution in terms of precision and increasing the stability of the maximum power point.

In this work, a maximum power point tracking (MPPT) controller based on artificial neural networks (ANN) is proposed to extract the maximum power at the output of the FL-M-160W PV module under stable weather conditions and in case of permanent variation of atmospheric conditions.

To achieve this goal, a data acquisition device has been associated with a pyranometer to record and extract the data during the testing phase. These data served as a learning base for the configuration and development of neural controllers. This controller uses irradiance and temperature as input parameters and voltage as output parameters. The proposed model is used to control the boost converter associated with the PV module. To evaluate the precision, the recovery time and the stability, the developed controller was simulated and tested under Matlab / Simulink in different atmospheric conditions and a comparison is made with the conventional methods.

This document is structured into five sections. Section 1 presents the topic introduction and the generality on PV systems is developed in section 2. A review of MPPT commands used for maximum power point tracking is presented in section 3 and section 4 is used to develop and model the neural MPPT controller. Finally, after modeling and simulation, results and discussion are presented in section 5 .

\section{Modeling Of The Of The Photovoltaic System}

Figure 1 illustrates the overall block diagram of the proposed system. It is a standalone PV system that includes a PV array use as a power generation source. This PV array is connected to the DC-DC boost converter that use ANN algorithm as maximum power point tracking technique to ensure the adaptation between the panel output voltage and the load.

\subsection{Electrical Modeling of the Solar Panel}

The electrical model of a PV cell is shown in figure 2. The electrical circuit of an ideal solar cell includes an Iph current source generated by light in parallel with a single diode. But in practice, no solar cell is ideal. Therefore, the shunt and serie resistors are added to the model to consider all the phenomena 
present during the conversion of light energy. In practice, the maximum current is delivered to the load when the series resistance Rs is very low and the shunt resistance Rsh is very large.

A solar cell produces generally a very low power output. To increase the output power of solar PV systems, solar cells are connected in series and parallel configurations to form PV modules whose equivalent model is described in figure 3 .

The current-voltage nonlinearity relationship of the PV module can be described mathematically using the basic equations $1,2,3,4,5$ and 6 .

Saturation current:

$$
I_{S}=I_{r S} *\left(\frac{T}{T_{n}}\right)^{3} * \exp \left[\frac{q E_{g 0}}{k n}\left(\frac{1}{T_{n}}-\frac{1}{T}\right)\right]
$$

1

Reverse saturation current:

$$
I_{r S}=\frac{I_{S C}}{\exp \left(\frac{V_{O C}}{n V_{T}}\right)-1}
$$

2

Photocurrent:

$$
I_{p h}=\frac{G}{G_{n}}\left(I_{s C}+K_{i} \cdot \Delta T\right)
$$

3

Current through the shunt resistance:

$$
I_{s h}=\frac{V_{d}}{R_{s h}}=\frac{V+R_{S} \cdot I}{R_{s h}}
$$

4

Output Current of a solar cell:

$\mathrm{I}=\boldsymbol{I}_{\boldsymbol{p h}}-I_{S}\left[\exp \left(\frac{\left(V+I R_{S}\right)}{n V_{T}}\right)-1\right]-\left\lfloor\frac{V+I R_{S}}{R_{p}}\right\rfloor$ 


$$
V_{T}=\frac{k T}{q}
$$

6

The output current of the considered PV module is given by:

$$
I_{P V}=n_{P} I_{p h}-n_{P} I_{S}\left[\exp \left(q \cdot \frac{V+R_{S} I}{n_{s} k T n}\right)-1\right]-\left[\frac{V+R_{S} I}{R_{s h}}\right]
$$

7

where $R_{S}$ is the series resistance of the solar cell and

$V$ is the output voltage of the cell and $n_{P}$ is the number of cells in parallel.

At the standard test condition, $\mathrm{AM}=1.5, \mathrm{G}=1 \mathrm{KW} / \mathrm{m}^{2}$ and $\mathrm{Tc}=25^{\circ} \mathrm{C}$. Then, the FL-M-160W PV module characteristics are given in table 1.

Tableau 1: Characteristics of the FL-M-160W solar module.

\begin{tabular}{|ll|}
\hline Parameters & Values \\
\hline Production tolerance & $+/-3 \%$ \\
Maximum power (Pmpp) & $160 \mathrm{~W}$ \\
Maximum power voltage (Vmpp) & $18.20 \mathrm{~V}$ \\
Maximum power current (Impp) & $8.80 \mathrm{~A}$ \\
Short-circuit current (Isc) & $9.33 \mathrm{~A}$ \\
Open circuit voltage (Voc) & $21.84 \mathrm{~V}$ \\
Number of cells in series (Ns) & 36 \\
Number of cells in parallel (Np) & 1 \\
\hline
\end{tabular}

\subsection{Analysis of PV Module Characteristics}

The FL-M-160W solar module output characteristics are shown in Figure 4, 5 and 6.

Figure 4 describes the non-linearity relationship of the $P(V)$ and I $(V)$ output characteristics of the PV array. On the $P(V)$ curve, a point where the power is maximum is observed. This is the maximum power point (MPP). As shown in Figures 5 and 6 , the characteristics I $(V)$ and $P(V)$ besides being non-linear also change with illumination and temperature [11]. A decrease in the irradiation $\mathrm{G}$ causes a decrease in the current followed by a very slight decrease in the voltage Voc and therefore a shift of the maximum power (Pmax) of the solar panel towards lower powers. As the temperature rises, the open circuit voltage Voc 
decreases dramatically while the current is virtually unchanged. The immediate consequence of varying environmental conditions is to vary the maximum output power of the PV generator.

\subsection{DC-DC Boost Converter}

To always extract the maximum power available at the terminals of the PV generator and to transfer it to the load, to ensure that the energy transfer is always possible and that it can be carried out under conditions of operation for the PV source and the load, a DC-DC converter is used [12]. Boost regulator is strongly recommended to follow the MPP because of its advantages over the buck converter. This switching power supply enables a higher value variable DC voltage source to be fabricated from a fixed input DC voltage source. The principle is to change the duty cycle of a rectangular signal to create a variable average voltage called Pulse Width Modulation (PWM). Figure 7 illustrates the boost converter model produced on Simulink, the specifications of which are contained in table 2 . The output voltage Vs is given by equation 8 .

$$
V_{s}=\frac{V_{e}}{1-\alpha}
$$

8

With a the duty cycle such that 0 cript $>$.

Tableau 2: DC-DC boost converter parameters

\begin{tabular}{|ll|}
\hline Parameters & Values \\
\hline Switching frequency $(\mathrm{khz})$ & 20 \\
\hline Inductance $\mathrm{L}(\mu \mathrm{H})$ & $10694.10^{\mathrm{e}}-8$ \\
\hline Input voltage $(\mathrm{V})$ & 18.20 \\
\hline Capacitors $\mathrm{C}$ and Ce $(\mu \mathrm{F})$ & $31575.10^{\mathrm{e}}-8$ \\
\hline
\end{tabular}

\section{Maximum Power Point Tracking}

In a PV system, the MPPT command can be defined as an algorithm which associated with an adaptation stage allows the system to operate in its optimal operating point and this whatever the atmospheric conditions (temperature and global sunshine) and of load value $[1,13]$. Various control laws suitable for permanent MPPT research exist in the literature. Although these techniques are used to follow the MPP with exactitude, the difference is generally observed in the complexity of implementation, the cost, the range of efficiency, the speed of convergence, the correct follow-up of the point of maximum power, the required sensors, the material necessary for the physical implementation and above all the behavior in the event of sudden changes in irradiation and / or temperature 


\subsection{Perturb \& Observe (P\&O) MPPT Command}

The principle of the P\&O command consists in performing a disturbance of the operating point of the PV generator by varying the voltage $\mathrm{Vpv}$ by a constant value $\Delta \mathrm{V}$, called the increment value or disturbance value, and to observe its effect on the resulting Ppv power. If the power increases $(\Delta P>0)$, we are therefore in the right direction, we continue the disturbance in the same direction otherwise $(\Delta P<0)$, so we move away from the MPP, we reverse the disturbance. Figure 8 gives the flowchart of this algorithm $[14,10]$

The P\&O algorithm is a classical algorithm widely used for its simplicity and ease of implementation, its precision, and its speed of reaction [15]. However, in case of rapidly variations of environmental condition, the P\&O algorithm presents a poor convergence [10]. This algorithm also presents some problems related to the oscillations around the MPP that it generates in steady state because the MPP search procedure must be repeated periodically, forcing the system to constantly oscillate around the MPP, once the latter is reached. These oscillations can be minimized by reducing the value of the disturbance variable. However, a low increment value slows down the search for MPP, so you have to find a compromise between precision and speed when choosing this update step that makes this command difficult to optimize.

\subsection{Incremental conductance (InC) MPPT Command}

The Incremental Conductance $(\mathrm{InC})$ method is used to address the problem of divergence encountered by the P\&O method in the case of a rapid change in sunlight. To calculate the MPP, the algorithm compares the conductance $\mathrm{G}$ with the incremental conductance $\Delta G$, and this by looking for the point of cancellation of the derivative of the power $[16,17]$. The evolution of the power of the PV generator relative to the voltage gives the position of the operating point relative to the MPP. When the power derivative is zero, it means that operating point is on the MPP, if it is positive the operating point is to the left of the MPP, when it is negative, it is to the right. A schematic description of this algorithm is shown in Figure 9 $[18,19]$.

The accuracy and speed with which the algorithm tracks the MPP depends on the size of the reference voltage increment or the duty cycle reference. Two main handicaps are reconciled with this method. The first is the oscillation of the operating point around the steady state MPP, the second is that the algorithm can easily lose track of the MPP if the solar radiation changes rapidly. When the irradiation varies instantly over time, the monitoring of the MPP evolves correctly. But, if the irradiation changes at a slope, the tracking will be poor. The algorithm is unable to determine whether the change in power is due to the voltage disturbance or the change in solar radiation. To verify the performance of this method, several authors choose an irradiation profile of different shapes for the simulations.

\subsection{Hill Climbing (HC)MPPT Command}

The principle of the Hill Climbing $(\mathrm{HC})$ algorithm is to give a disturbance on the duty cycle which results in a displacement of the operating point along the power-duty cycle characteristic of the photovoltaic generator. The perturbation is applied for several iterations on the parameter a by incrementing or 
decrementing it by $\Delta \mathrm{a}$ until the derivative is zero. Theoretically, when the maximum power point is reached, the search should stop. The Hill Climbing algorithm is developed in Figure 10 diagram [20, 21].

This technique is easy to implement, but its main limitations are oscillations around the MPP in steady state and an occasional loss of the search for MPP during rapid change in weather conditions.

To remedy the various problems associated with the various classical algorithms, artificial intelligence techniques such as fuzzy logic and neural networks have been introduced.

\subsection{Artificial Neural Network}

An artificial neural network (ANN) is an information processing system made up of a number of simple, highly interconnected processors called neurons, similar to biological brain cells [22, 23]. These neurons

are interconnected by numerous weighted links, over which signals can pass. Each neuron receives many signals on its incoming connections and produces a single outgoing response. These networks have exceptional pattern recognition and learning capacities [23]. Recent ANN applications have shown that they have enormous potential to overcome the difficult tasks of processing and interpreting data. The use of the neural network in the synthesis of the MPPT controller for the optimization of the power of the photovoltaic panels has proven to be a very effective solution in terms of precision and increasing the stability of the maximum power point compared to conventional techniques ( $P \& O, \ln C, H C)$ [13]. In this work, a multilayer perceptron neural network is used to extract the maximum output power from the FL-M160W PV module.

\section{Neural Modeling Of The Pv Generator 4.1. Experimental test}

the construction and configuration of the neuronal MPPT controller involves the establishment of a database for the training of the network. The recording of real data during the test phase made it possible to build this database. Figures 11 and 12 represent the experimental setup used for data acquisition. This device includes an acquisition card used for recording voltage and current data, a Benning Sun 2 pyranometer and a Felicity Solar photovoltaic panel connected to the boost converter. The pyranometer measures solar irradiance, panel surface temperature and ambient temperature. It also determines the orientation and inclination of the panel according to the latitude of the site.

After this test phase, the recorded data will be optimized to approximate the output of the neural model and estimate the maximum output power of the PV panel based on the variation in illumination and temperature. Figure 13 illustrates the network developed to estimate the MPP. It is a multilayer perceptron (MLP) consisting of an input layer with two neurons that correspond to the two input variables, namely the illumination $\mathrm{G}$, the temperature Tpv, a hidden layer of 10 neurons and a layer of output with a single neuron representing the target (an output variable) to approach the desired output which is the optimum voltage. this network uses the sigmoid-type activation function for the hidden layer and a linear function 
for the output layer. To adjust the weights and biases in order to satisfy the optimization criterion, the backpropagation algorithm is used as a supervised learning method.

\subsection{Development of the ANN model on Matlab}

The data issued from experimental tests were divided into two categories (training data and test data) to develop and configure the ANN model. Each type of data is an input (Irradiance, Temperature) / output (voltage) pair. 1159 items were used for training and 194 items for testing. Figure 14 illustrates the Matlab model of the neural network with two neurons in the input layer, 10 neurons in the hidden layer and one neuron in the output layer.

The developed network training performance curve shown in Figure 15 displays a mean square error (MSE) of 0.05271 typically achieved after 998 epochs. This network is then used to perform some tests. Figure 16 shows that the outputs of the neural model correspond substantially to the target values.

After a test carried out on 21 target points including Vppm. A comparison is made between the real voltage output values and the neural output values. Table 3 shows that the neural outputs are close to the target values according to the graphs in Figure 17. The neuronal output provides an optimal voltage Vopt close to the real data. This can lead to conclude on the interest of the synthesis of the neural controller in the MPPT command.

The developed neural controller is shown in Figure 18. In this model, the irradiance $G$ and the panel surface temperature Tpv are the input variables while the network output is the optimal voltage Vopt. This voltage is then compared to the reference voltage $\mathrm{Vpv}$ of the PV generator and the error is given to generate operating signals. The generated PWM signals manage the duty cycle of the DC - DC converter to adjust the operating point of the PV module.

Tableau 3: Actual output data and Vmpp neural network from irradiance and temperature data 


\begin{tabular}{|c|c|c|c|c|c|}
\hline $\mathbf{N}^{\circ}$ & Test point & Irradiance $G\left(W / m^{2}\right)$ & Temperature $\operatorname{Tpv}\left({ }^{\circ} \mathrm{C}\right)$ & $\operatorname{Vpv}(V)$ & Vopt (V) \\
\hline 1 & {$[1000,25]$} & 1000 & 25 & 18,20 & 18,21 \\
\hline 2 & {$[354,36]$} & 354 & 36 & 15,85 & 15,0642 \\
\hline 3 & {$[400,35]$} & 400 & 35 & 17,77 & 16,1392 \\
\hline 4 & {$[250,35]$} & 250 & 35 & 12,27 & 11,0636 \\
\hline 5 & {$[740,37]$} & 740 & 37 & 18,51 & 17,8196 \\
\hline 6 & {$[670,41]$} & 670 & 41 & 18,62 & 17,4532 \\
\hline 7 & {$[1019,41]$} & 1019 & 41 & 18,72 & 17,7355 \\
\hline 8 & {$[1103,42]$} & 1103 & 42 & 18,76 & 17,8025 \\
\hline 9 & {$[1010,43]$} & 1010 & 43 & 18,62 & 17,5235 \\
\hline 10 & {$[930,45]$} & 930 & 45 & 18,16 & 17,5235 \\
\hline 11 & {$[804,45]$} & 804 & 45 & 18,23 & 17,1583 \\
\hline 12 & {$[820,41]$} & 820 & 41 & 18,37 & 17,6144 \\
\hline 13 & {$[614,41]$} & 614 & 41 & 18,23 & 17,2957 \\
\hline 14 & {$[950,42]$} & 950 & 42 & 18,44 & 17,5954 \\
\hline 15 & {$[850,42]$} & 850 & 42 & 18,51 & 17,5318 \\
\hline 16 & {$[210,33]$} & 210 & 33 & 10,14 & 9,3559 \\
\hline 17 & {$[154,31]$} & 154 & 31 & 9,15 & 8,1387 \\
\hline 18 & {$[711,42]$} & 711 & 42 & 18,08 & 17,4536 \\
\hline 19 & {$[460,37]$} & 460 & 37 & 17,98 & 17,2223 \\
\hline 20 & {$[507,38]$} & 507 & 38 & 18,55 & 17,3415 \\
\hline 21 & {$[317,35]$} & 317 & 35 & 14,43 & 13,4759 \\
\hline
\end{tabular}

\section{Results And Discussion}

Figure 19 describes the model of the stand-alone PV system developed in Simulink. It consists of a PV panel, a DC-DC boost converter and a load. the developed ANN MPPT controller is used to drive the converter in order to run the generator at its maximum power point.

The Felicity Solar PV FL-M-160W module used for the simulation produces $160 \mathrm{~W}$ of power under standard test conditions. To validate the efficiency and robustness of the ANN MPPT controllers, 
simulations are carried out under standard environmental conditions and in the case of rapidly change of environmental conditions.

\section{1. standard environmental conditions}

Under standard environmental conditions, the simulations are carried out under fixed conditions of illumination $\mathrm{G}=1000 \mathrm{w} / \mathrm{m}^{2}$ and temperature $\mathrm{T}=25^{\circ} \mathrm{C}$. The output characteristics of the neural controller are illustrated by figures 18,19 and 20 .

As shown in Figure 20, the output power of the neural MPPT is very stable with a very low response time of around $0.015 \mathrm{~s}$. However, there are weak oscillations that remain because this power varies between 154.5 and $155.8 \mathrm{~W}$. The output current is relatively low while the output voltage is very high, which is more stable, which makes it possible to have a better efficiency of the power of the output panel.

Figure 23 compares neural and conventional controllers. The ANN controller can accurately track the maximum power point of the PV generator. It provides more stable power output and closer to MPP compared to conventional MPPT and converges quickly to the new MPP. Conversely, although the P\&O, InC and HC controls follow the MPP perfectly, they are slower and only arrive at the MPP after a delay. The recovery time is approximately $0.02 \mathrm{~s}$ for these techniques.

\subsection{Rapidly change of environmental conditions}

Under rapidly change conditions, there are sharp variations in irradiance and / or temperature. However, the variation in temperature has little influence on the output power compared to the variation in sunlight. simulations are realized with a constant temperature equal to $25^{\circ} \mathrm{C}$ for a solar irradiation which suddenly deviates from 1000 to $700 \mathrm{~W} / \mathrm{m}^{2}$ then from 700 to $1200 \mathrm{~W} / \mathrm{m}^{2}$ and this for $1 \mathrm{~s}$. Figure 24 illustrates the output power of the generator in unstable conditions.

To evaluate the robustness, the rapidity, the precision and the speed of convergence of the neuronal technique developed as well as its capacity to follow the MPP under the conditions of sudden variation of the environmental conditions, a comparison is made with the classical methods (Figure 25, 26 and 27).

During rapid changes in climatic conditions, the output characteristics (maximum power, voltage and current) provided by the PV generator varies proportionally with irradiation as shown in Figures 23, 24 and 25 . When irradiation is $1000 \mathrm{~W} / \mathrm{m}^{2}$, the maximum power supplied by the $\mathrm{PV}$ generator stabilizes around $156 \mathrm{~W}$ for the different MPP tracking techniques. When the sun goes from 1000 to $700 \mathrm{~W} / \mathrm{m}^{2}$, this maximum power is $108 \mathrm{~W}$ for $\mathrm{ANN}, 99 \mathrm{~W}$ for $\mathrm{P} \& 0,88 \mathrm{~W}$ for InC and finally $85 \mathrm{~W}$ for HC. Finally, when going from 700 to $1200 \mathrm{~W} / \mathrm{m}^{2}$, Pmax becomes equal to $188 \mathrm{~W}$ for ANN, $170 \mathrm{~W}$ for P\&O and InC and $178 \mathrm{~W}$ for $\mathrm{HC}$. There are significant oscillations of conventional techniques compared to ANN first in transient and steady state as well. The sudden variation in sunlight greatly disturbs conventional controllers. In our case, for low irradiation, the $\mathrm{HC}$ controller is less cost effective compared to other conventional techniques, but it becomes better when the irradiation becomes greater. These results show that MPPT controls allow adaptation of PV generator and load to MPP with optimal transfer of PV power. 


\section{Conclusion}

In this work devoted to the neuronal modeling of the MPPT command for a PV generator in disturbed conditions, the PV system elements have been modeled in Matlab / Simulink. Subsequently, a review on MPPT commands was developed and allowed to highlight the difficulties of classical MPPT commands in the search for MPP and to give particular interest in the use of neural networks in the pursuit of maximum power point. From the experimental tests carried out on site, a database was created and made it possible to develop the neural MPPT controller. After learning, testing and verification phases the block was inserted into the system to regulate the adaptation stage. Then, simulation of the behavior of the PV system under stable and disturbed environmental conditions has been done to analyze the characteristics obtained at the output of the panel. A comparative study between the neural MPPT controller and conventional algorithms reveals robustness, high stability and very low response time compared to conventional methods.

\section{References}

[1] S. Leva and D. Zaninelli, "Technical and financial analysis for hybrid photovoltaic power generation systems," WSEAS Transactions on Power, vol. 5, no. 1, p. 831-838, 2006.

[2] R. Contino, S. Leva and D. Zaninelli, "Integrated renewable sources for supplying remote power systems," WSEAS Transactions on power systems,, vol. 2, no. 2, pp. 41-48, 2007.

[3] T. Markvart, Solar electricity, Chichester: John Wiley \& Sons, 1994.

[4] D. Rekioua and E. Matagne, Optimization of photovoltaic power systems: modelization, simulation and control, London: Springer-Verlag, 2012.

[5] E. Koutroulis, K. Kalaitzakis and N. C. Voulgaris, “Development of a microcontroller-based, photovoltaic maximum power point tracking control system," IEEE Trans Power Electron , vol. 16, no. 1, p. 46-54, 2001.

[6] H. S.-H. Chung, K. Tse, S.Y.RonHui, C.M.Mok and M.T.Ho, "A novel maximum power point tracking technique for solar panels sing SEPIC or Cukconverter," IEEE Transactions on power electronics, vol. 18, no. 3, pp. 717-724, May 2003.

[7] W. R.-J. Wai, W. Wen-Hung and L. Jun-you, "Grid-connected photovoltaic Generation system with Adaptive step-perturbation method and tracking scheme," IEEE Transactions on Industrial electronics, pp. 224-22, Nov.2006.

[8] A. Govind, "Fuzzy Logic based Maximum Power Point Tracker for a PV System," IOSR Journal of Electrical and Electronics Engineering (IOSR - JEEE), vol. 5, no. 4, p. 13 - 21, May -Jun 2013.

[9] G. Li and H. A. Wang, "Novel stand-alone PV generation system based on variable step size INC MPPT and SVPWM control," In: Proceedings of the IEEE 6th international power electronics and motion control 
conference, IEEE-IPEMC'09, pp. 2155-2160, 2009.

[10] N. Femia, G. Petrone, G. Spagnuolo and M. Vitelli, “A technique for improving P \& O MPPT performances of double-stage grid-connected photovoltaic systems," IEEE Trans Ind Electron, vol. 56, no. 11, p. 4473-82, 2009.

[11] D. Rekioua and E. Matagne, "Optimization of Photovoltaic Power Systems," Springer Science and Business Media LLC, 2012.

[12] S. Z. Hassan, H. Li, T. Kamal, U. A. glu, S. Mumtaz and L. Khan, "Neuro-Fuzzy Wavelet Based Adaptive MPPT Algorithm for Photovoltaic Systems," MDPI, Energies, vol. 10, no. 394, 2017.

[13] M. Sabir, H. Abdelghani and L. Abdelhamid, "A new variable step size neural networks MPPT controller: Review, simulation and hardware implementation," Renewable and Sustainable Energy Reviews, Elsevier, vol. 68, p. 221-233, 2017.

[14] F. C. B. Nzoundja, M. Kamta and P. Wira, "A comprehensive assessment of MPPT algorithms to optimal power extraction of a PV panel," Journal of Solar Energy Research, vol. 4, no. 3, pp. 172-179, 2019.

[15] N. Femia, G. Petrone, G. Spagnuolo and M. Vitelli, "Optimization of perturb and observe maximum power point tracking method," IEEE Trans Power Electron, vol. 20, no. 4, p. 963-73, 2005.

[16] A. Belkaid, I. Colak and O. Isik, "Photovoltaic maximum power point tracking under fast varying of solar radiation," Applied Energy, 2016.

[17] I. S. Kim, "Sliding mode controller for the single-phase grid-connected photovoltaic system. Appl Energy 2006;83:1101-15.," Appl Energy , vol. 83, p. 1101-1115, 2006.

[18] K. H. Hussein, I. Muta, T. Hoshino and M. Osakada, "Suivi de la puissance photovoltaïque maximale : un algorithme pour des conditions atmosphériques en évolution rapide," IEE Proceedings-Generation, Transmission and Distribution, vol. 142, pp. 59-64, 1995.

[19] A. R. Reisi, M. H. Moradi and B. S. Jamas, "Classification and comparison of maximum power point tracking techniques for photovoltaic system: a review," Renew Sustain Energy Rev, vol. 19, p. 433-43, 2013.

[20] M. Razzazan, Z. Mirbagheri and A. Ramezani, "Maximum Power Point Tracking Using Constrained Model Predictive Control for Photovoltaic Systems," Journal of Solar Energy Research (JSER), Springer, vol. 2, no. 2, pp. 19-24, 2017.

[21] N. A. Kamarzaman and C. W. Tan, "A comprehensive review of maximum power point tracking algorithms for photovoltaic systems," Renew Sustain Energy Rev, vol. 37, p. 585-98, 2014. 
[22] M. Mokhtar and M. Marie, Engineering applications of matlab 5.3 and simulink3, London b: springerverlag london berlin heidelberg, 538 pages, 2000.

[23] S. Krishna and K. R. Padiyar, "Transient stability assessment using artificial neural networks," IEEE Trans Power Syst, p. 627-632, 2000.

\section{Figures}

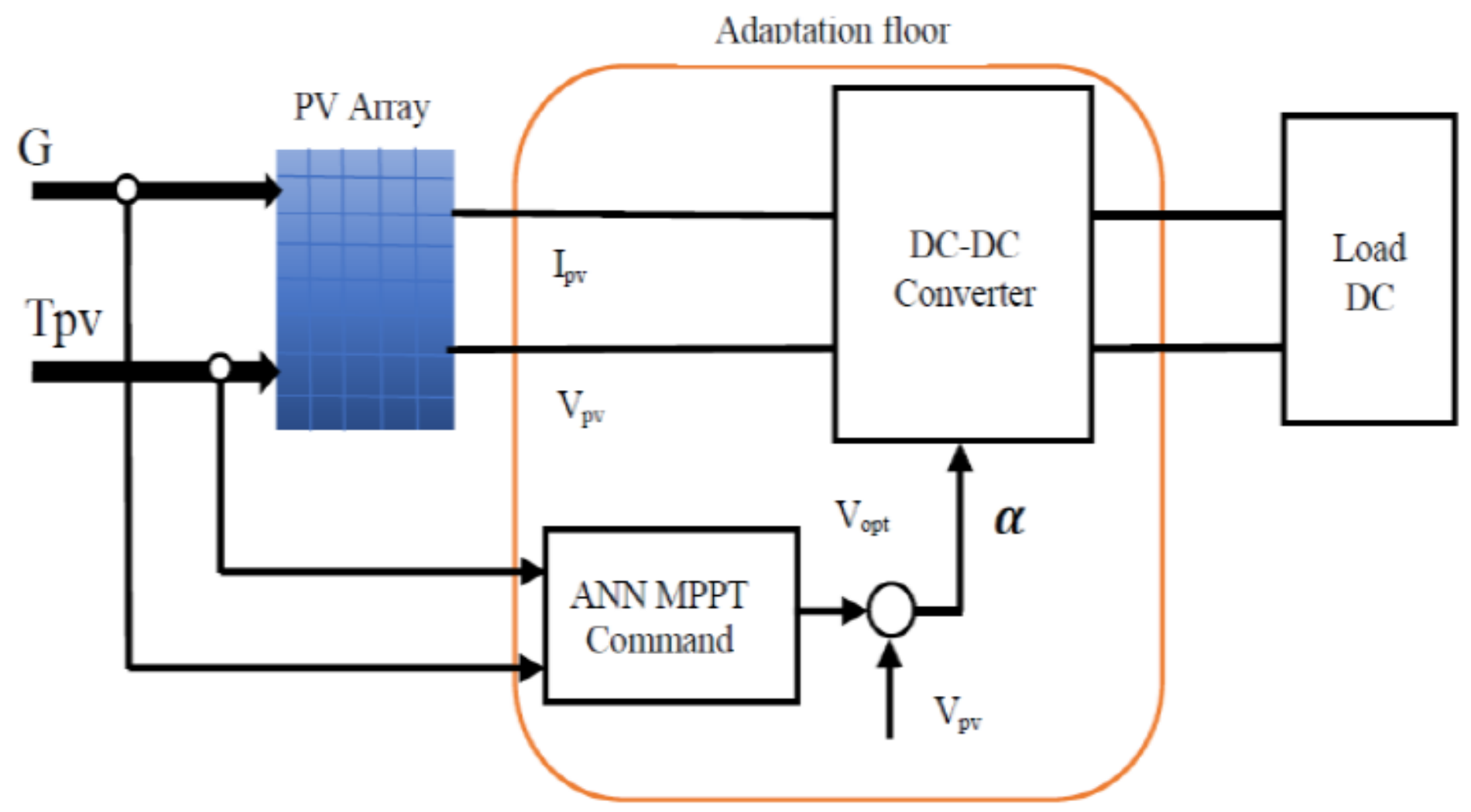

Figure 1

Overall block diagram of the PV system proposed. 


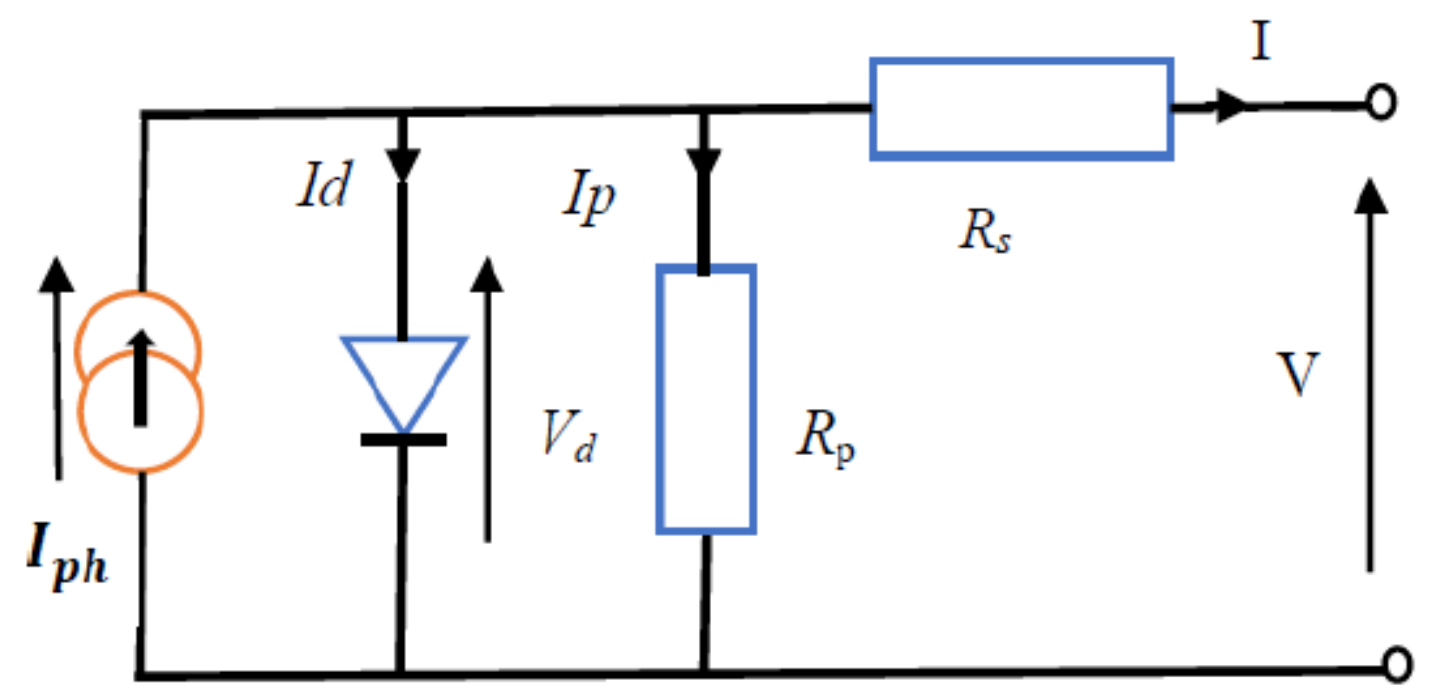

Figure 2

Equivalent diagram of a PV cell.

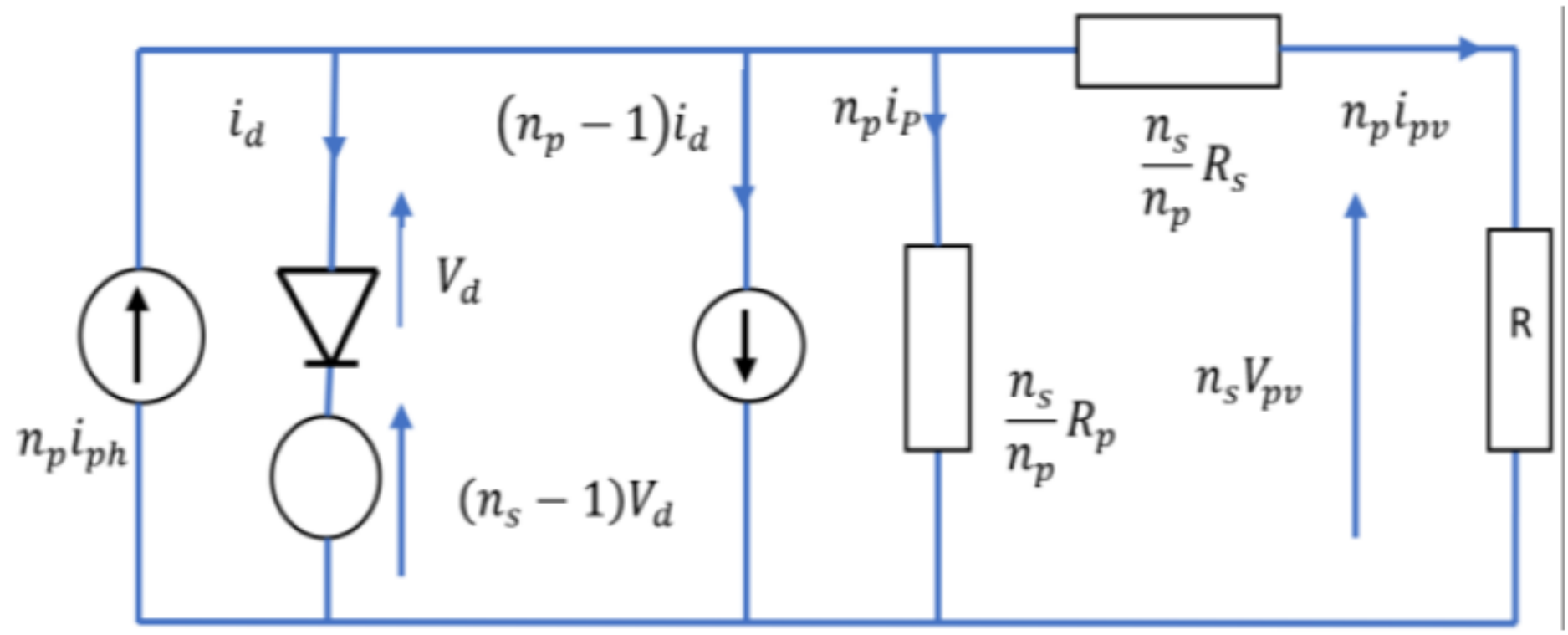

Figure 3

Equivalent circuit of a PV module. 

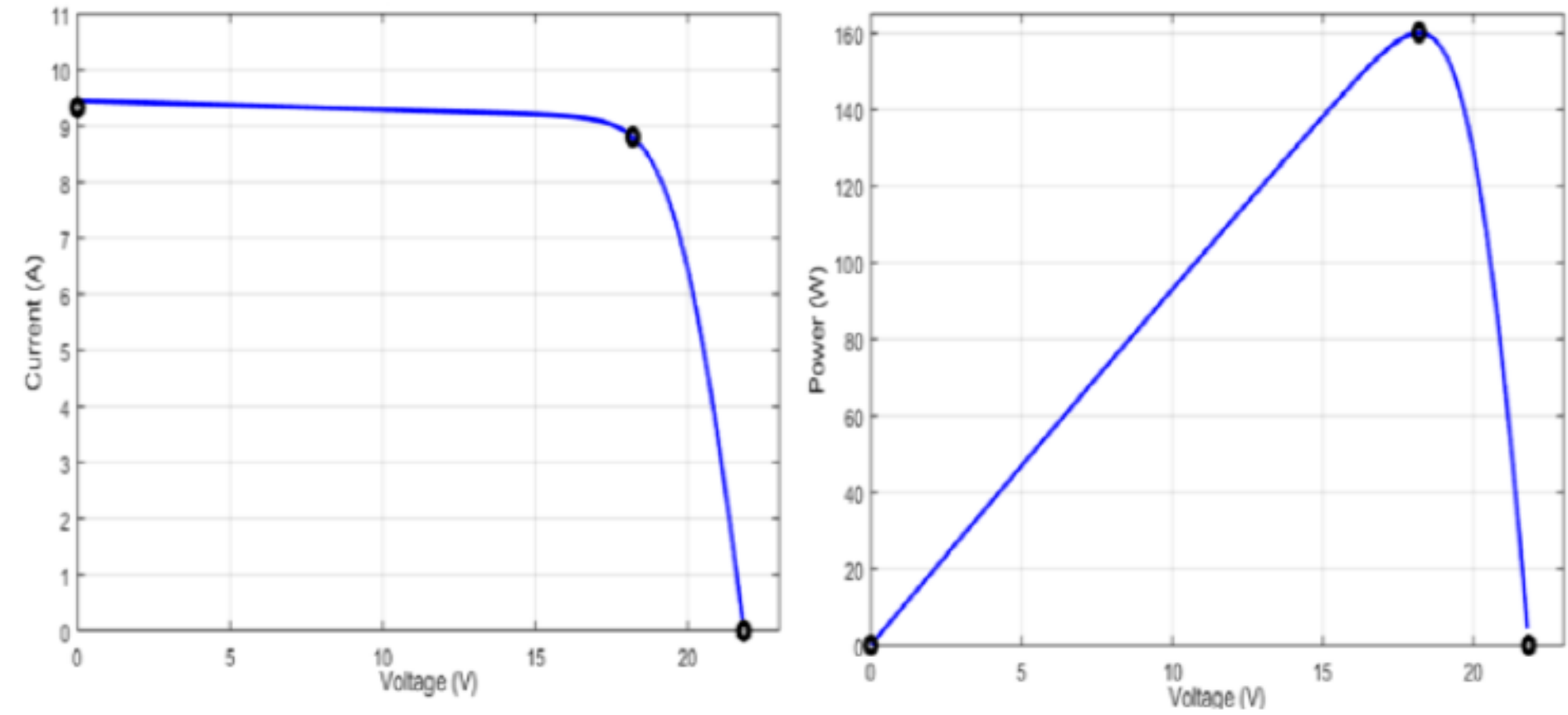

Figure 4

$\mathrm{I}(\mathrm{V})$ and $\mathrm{P}(\mathrm{V})$ characteristics of the PV module
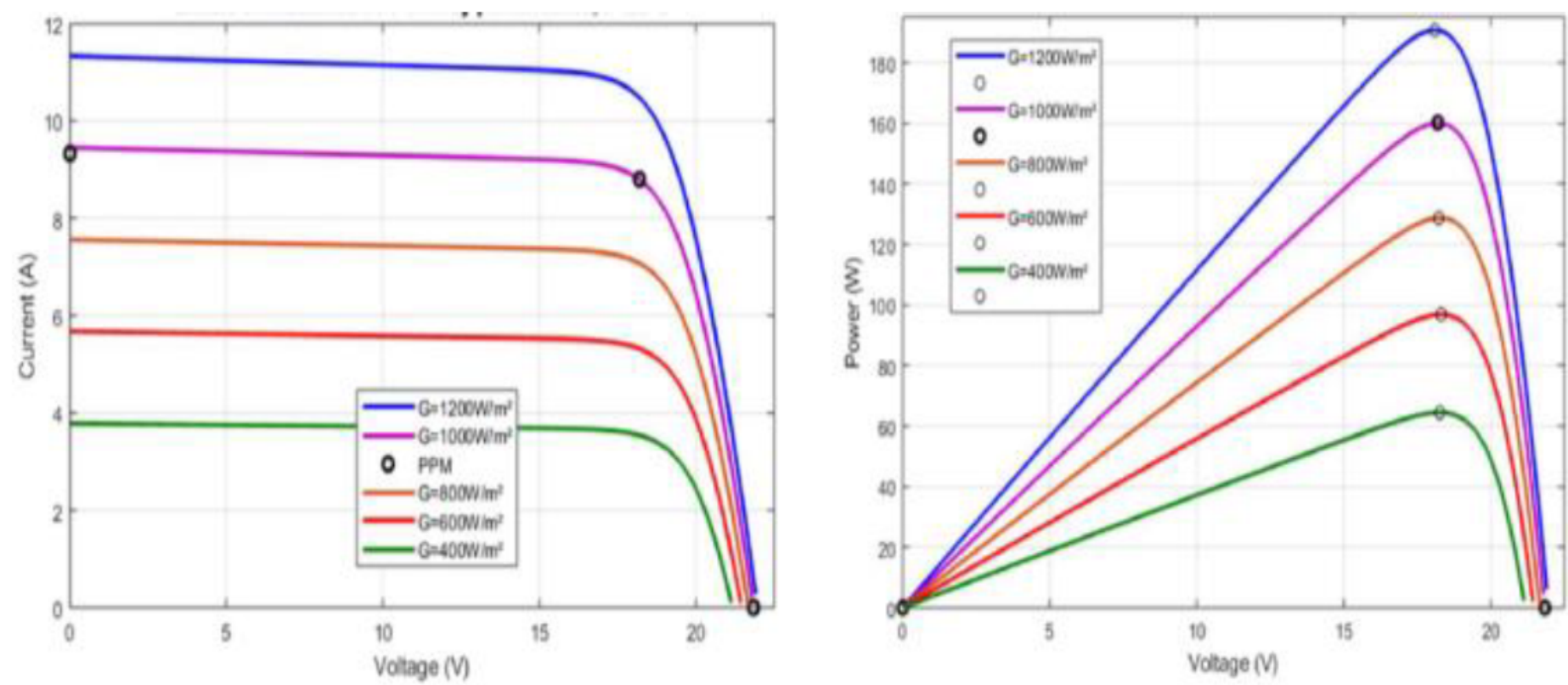

Figure 5

Irradiation variation on $\mathrm{I}(\mathrm{V})$ and $\mathrm{P}(\mathrm{V})$ characteristics $\left(\mathrm{T}=25^{\circ} \mathrm{C}\right)$. 

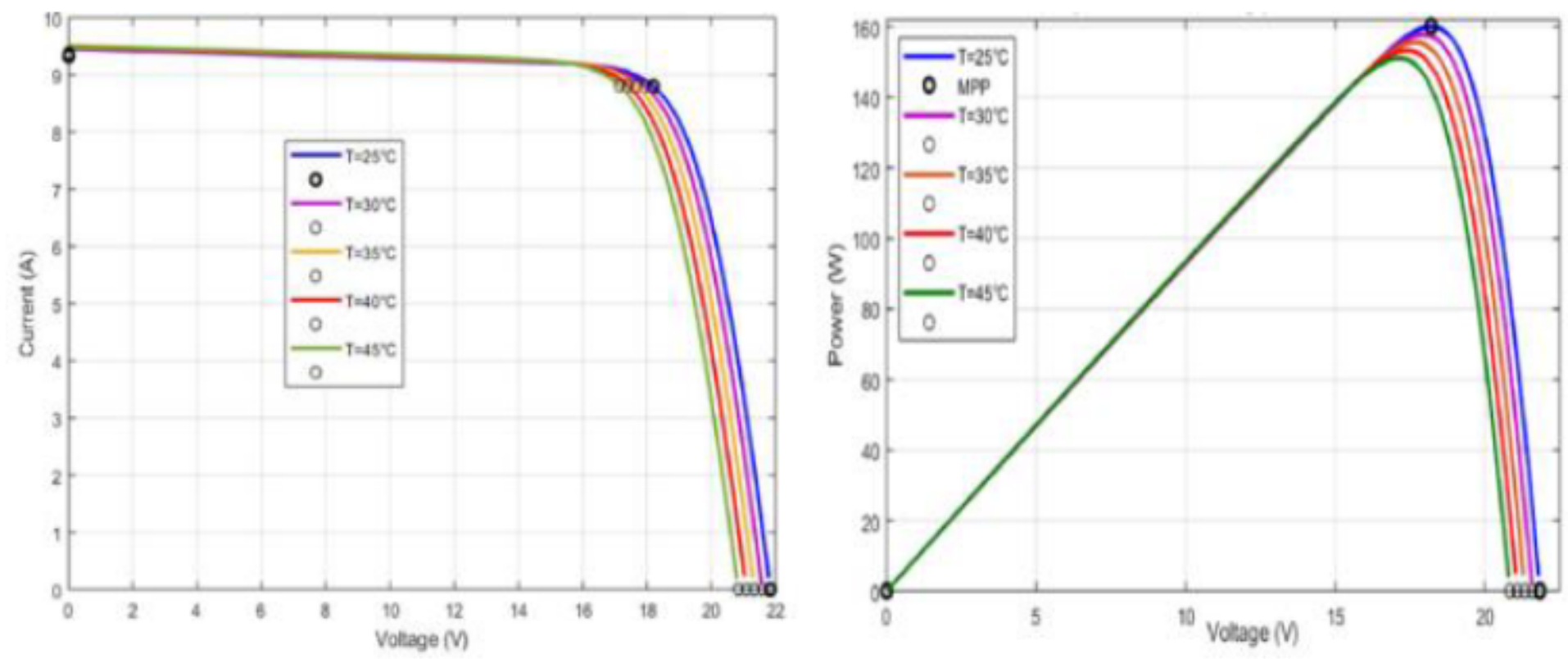

Figure 6

Temperature variation on I $(\mathrm{V})$ and $\mathrm{P}(\mathrm{V})$ characteristics $\left(\mathrm{G}=1000 \mathrm{~W} / \mathrm{m}^{2}\right)$.

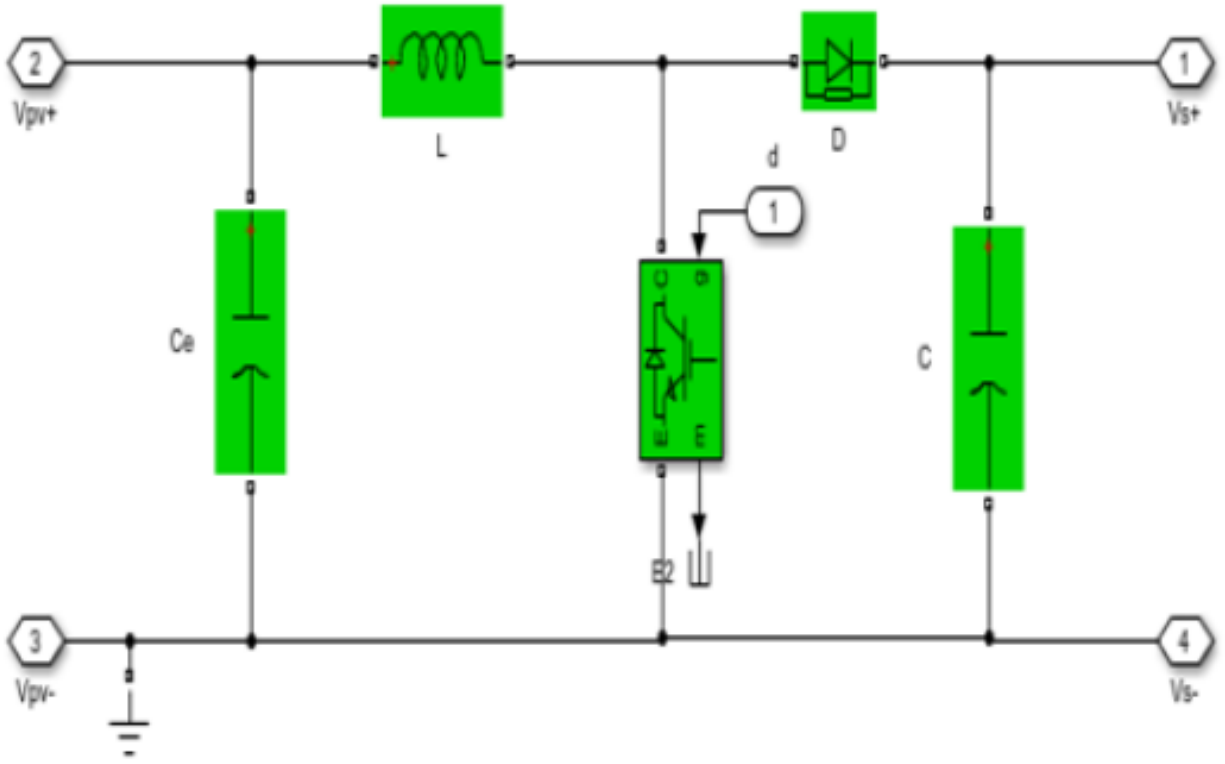

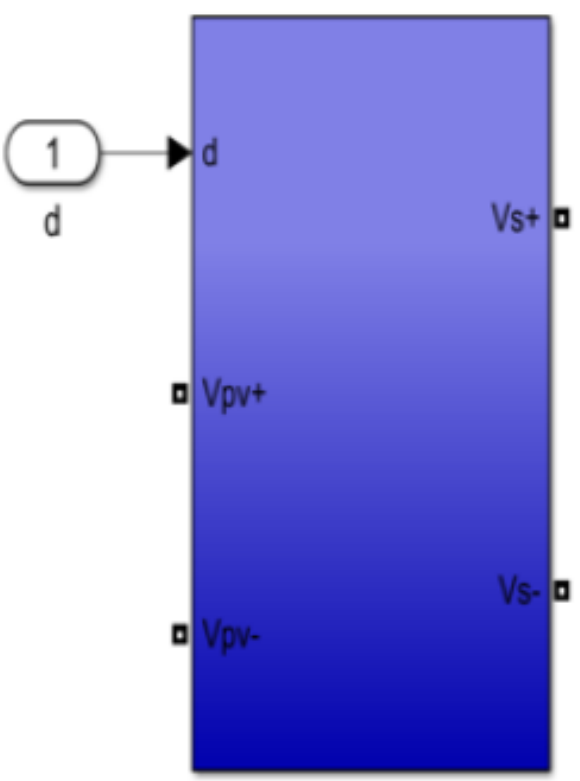

hacheur boost

Figure 7

Simulink model of the boost converter. 


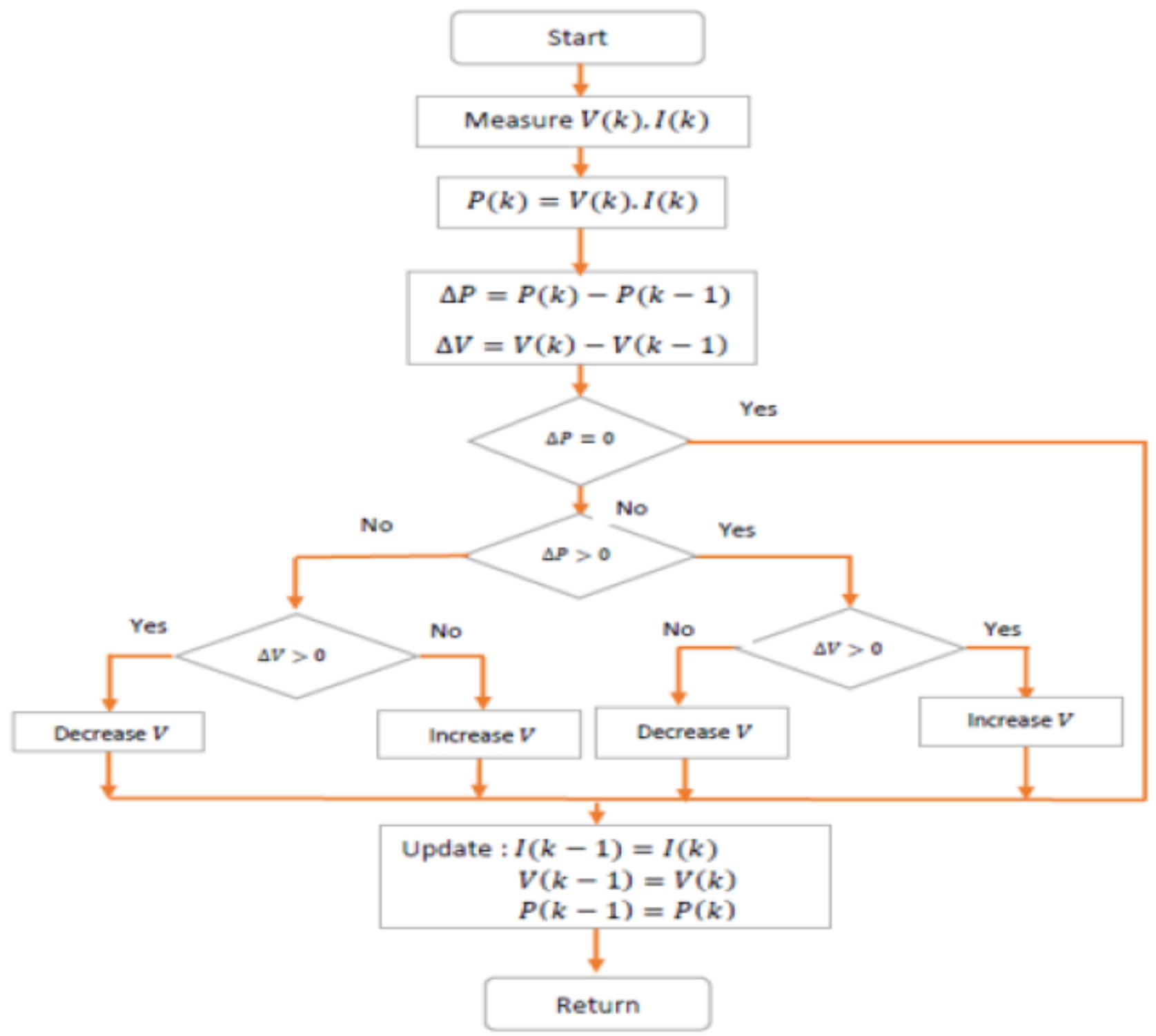

Figure 8

Perturb \& Observe (P\&O) algorithm. 


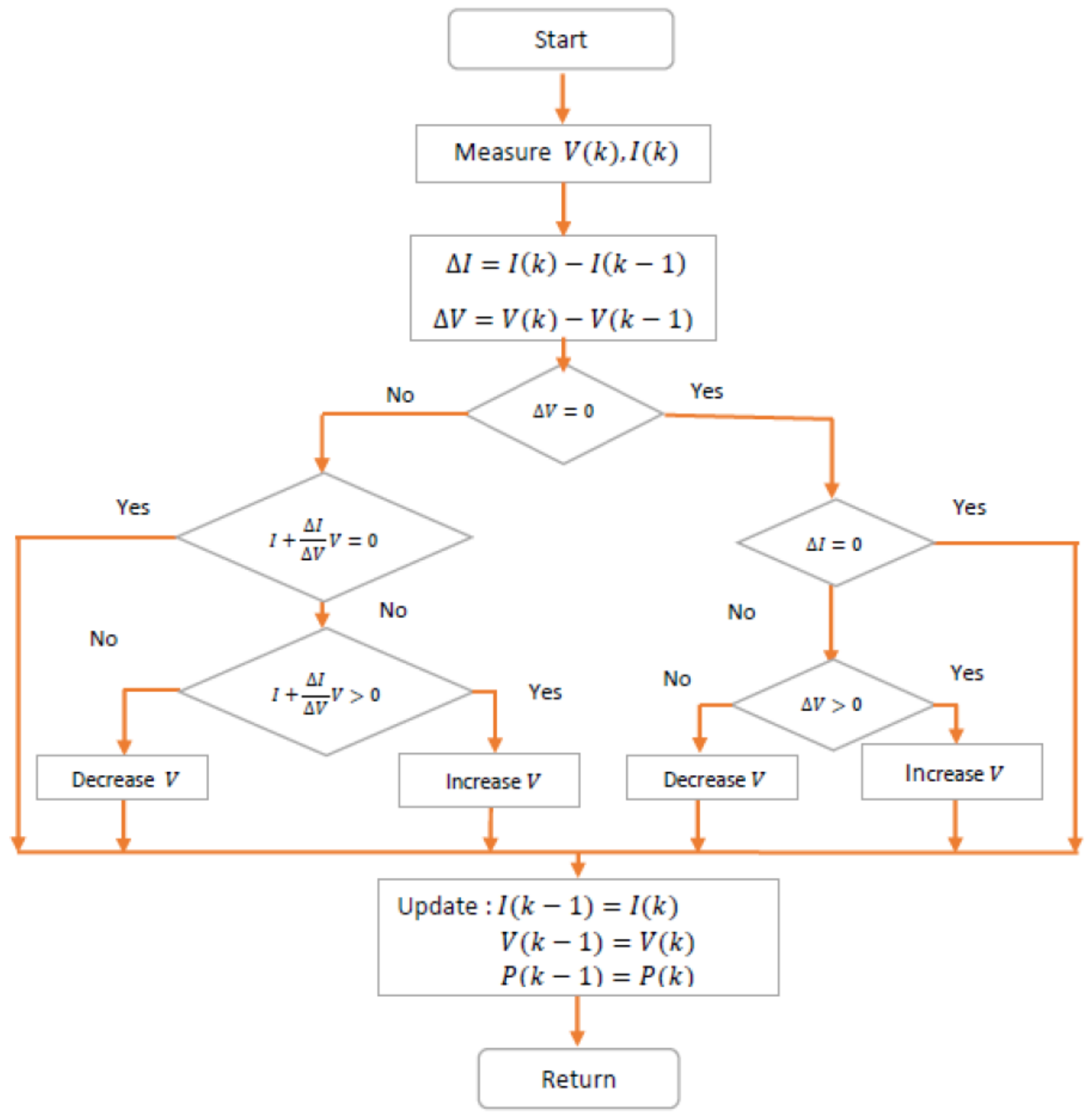

Figure 9

Incremental Conductance (InC) algorithm. 


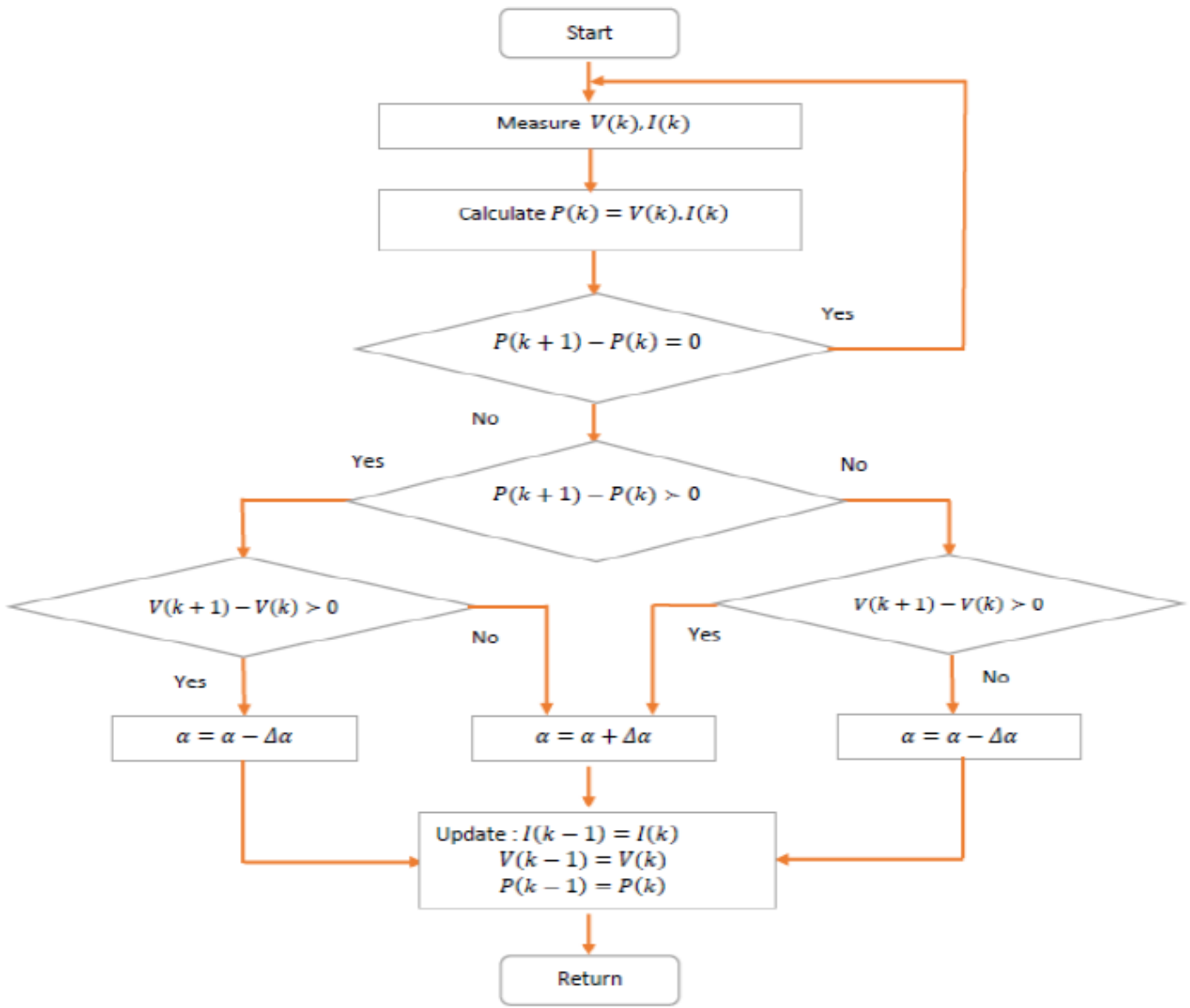

Figure 10

Hill Climbing (HC) algorithm. 


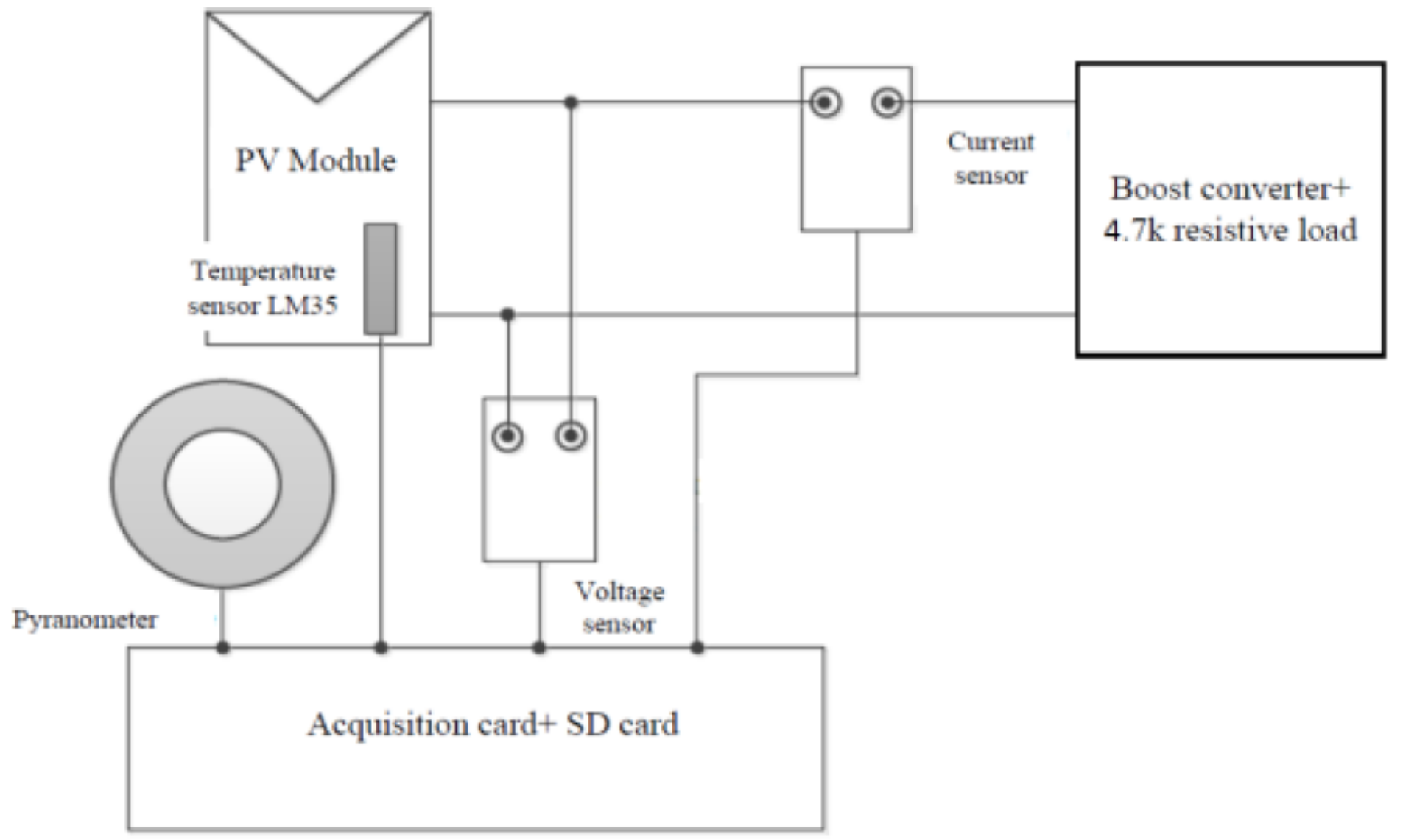

Figure 11

Experimental device for data acquisition. 


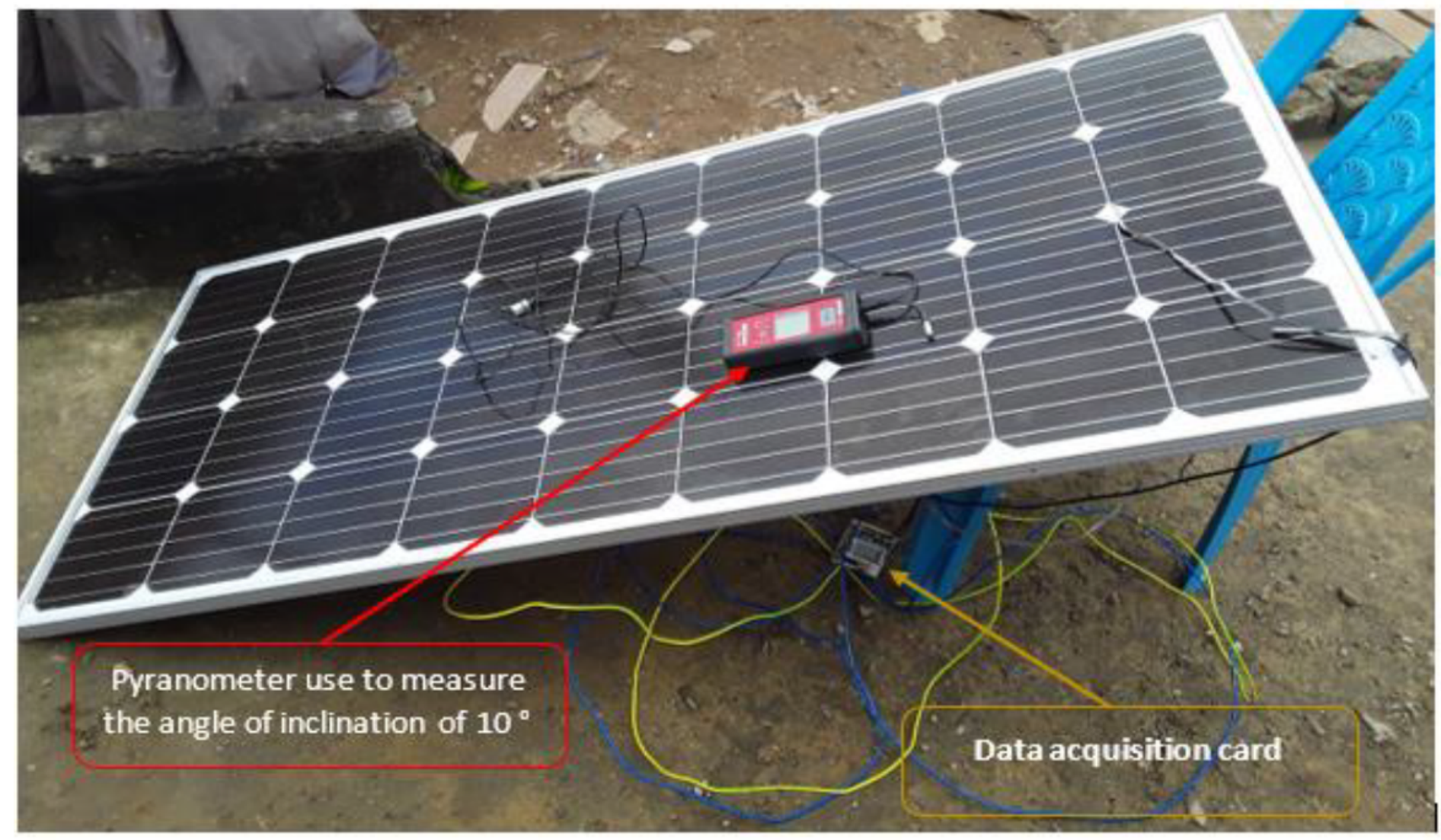

Figure 12

Experimental data acquisition device

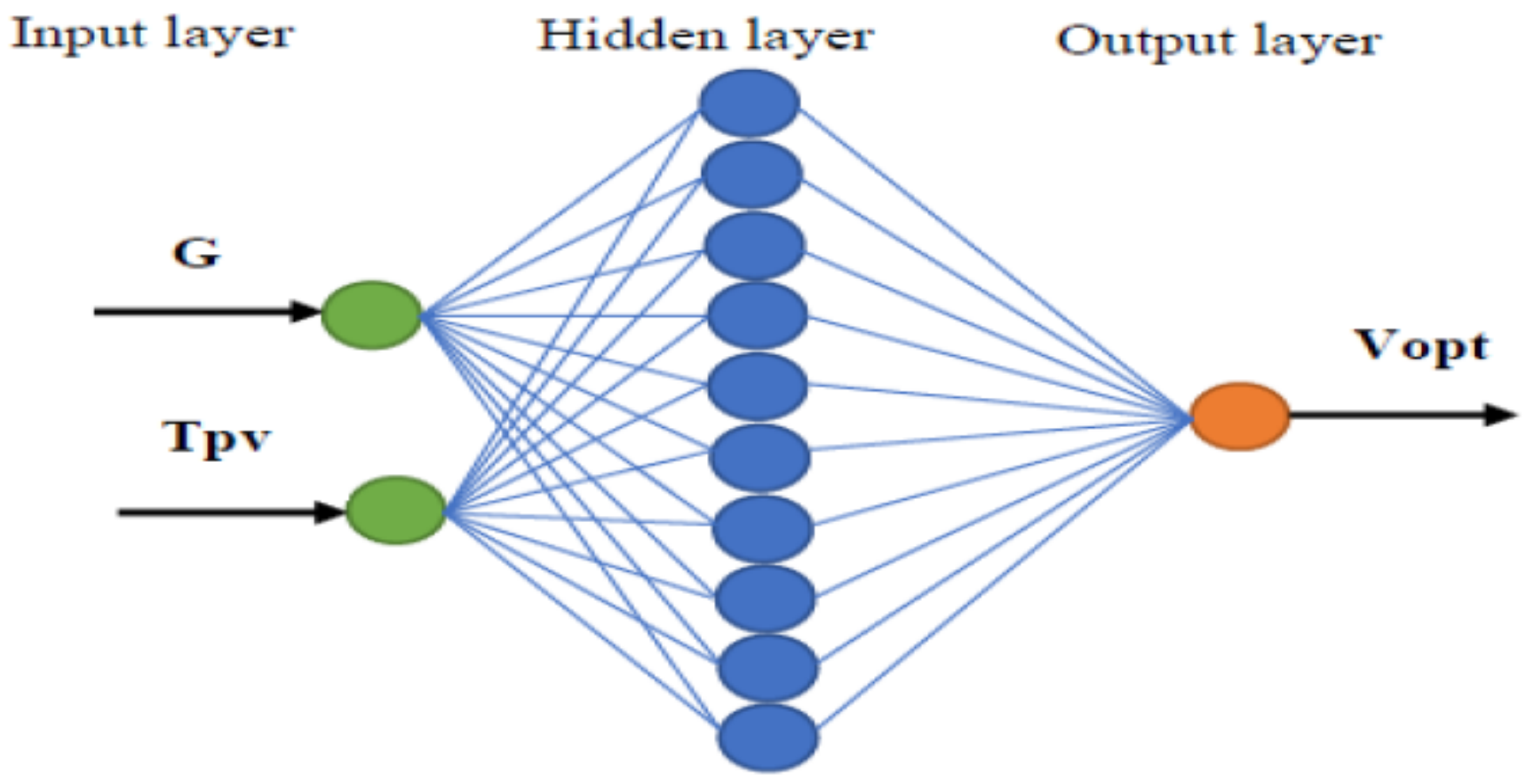

Figure 13 


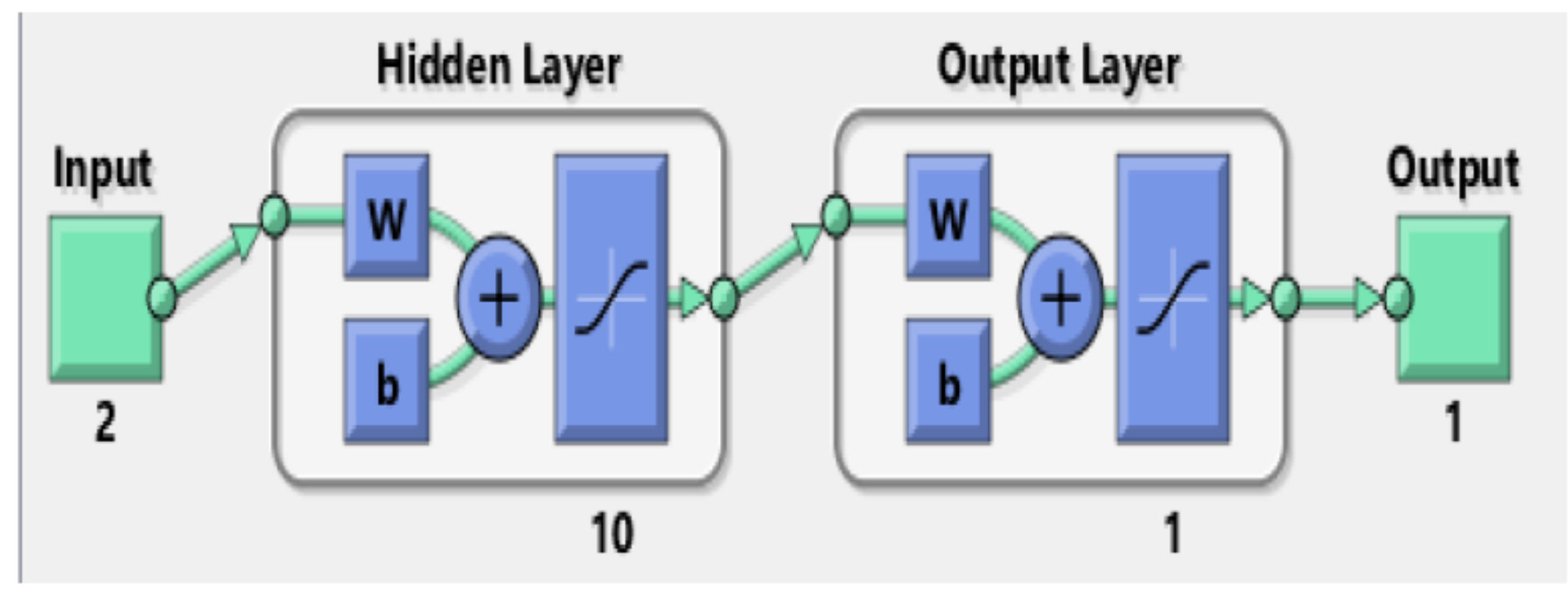

Figure 14

Structural model of the neural network in Matlab

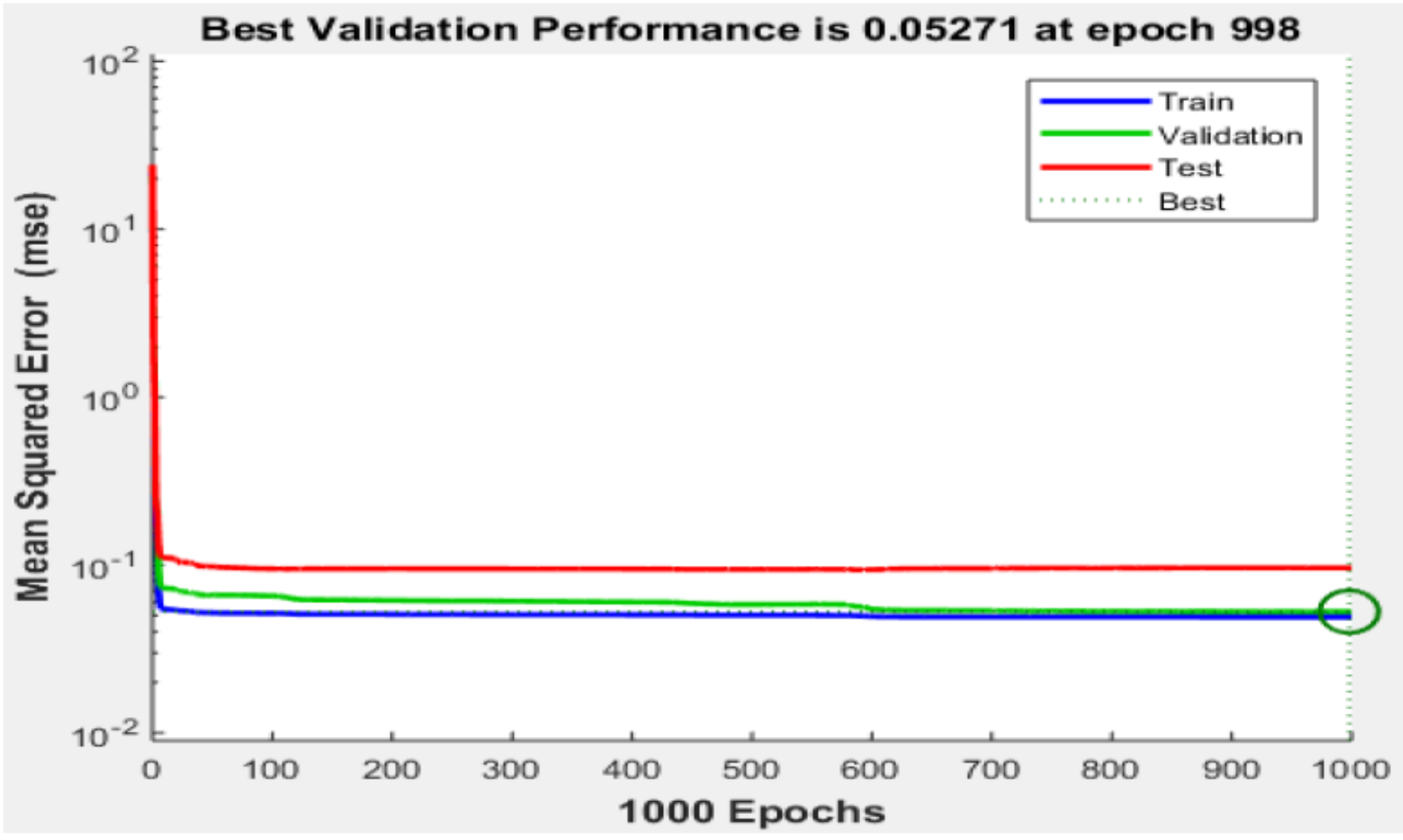


Training performance curve.
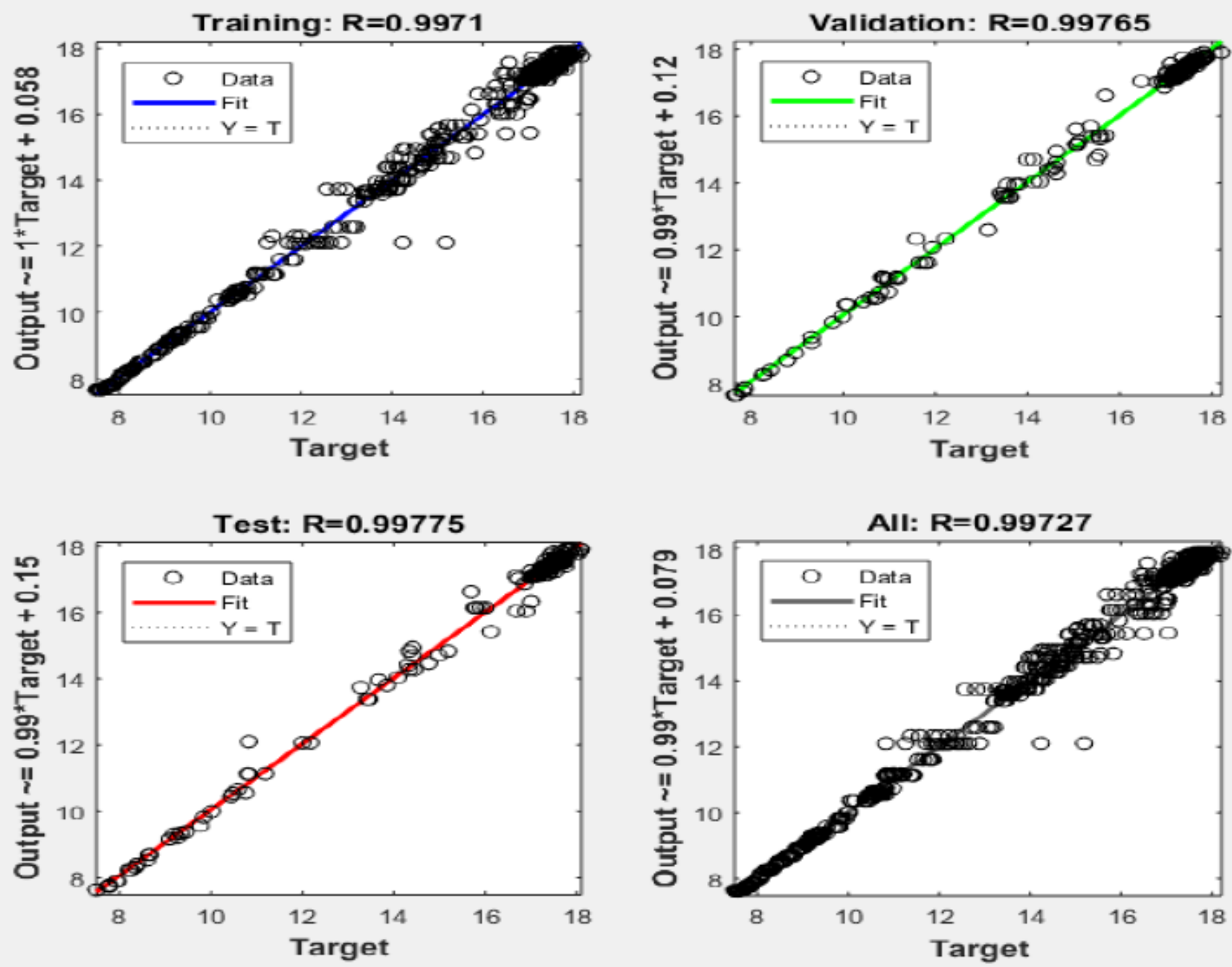

Figure 16

Regression Curves. 


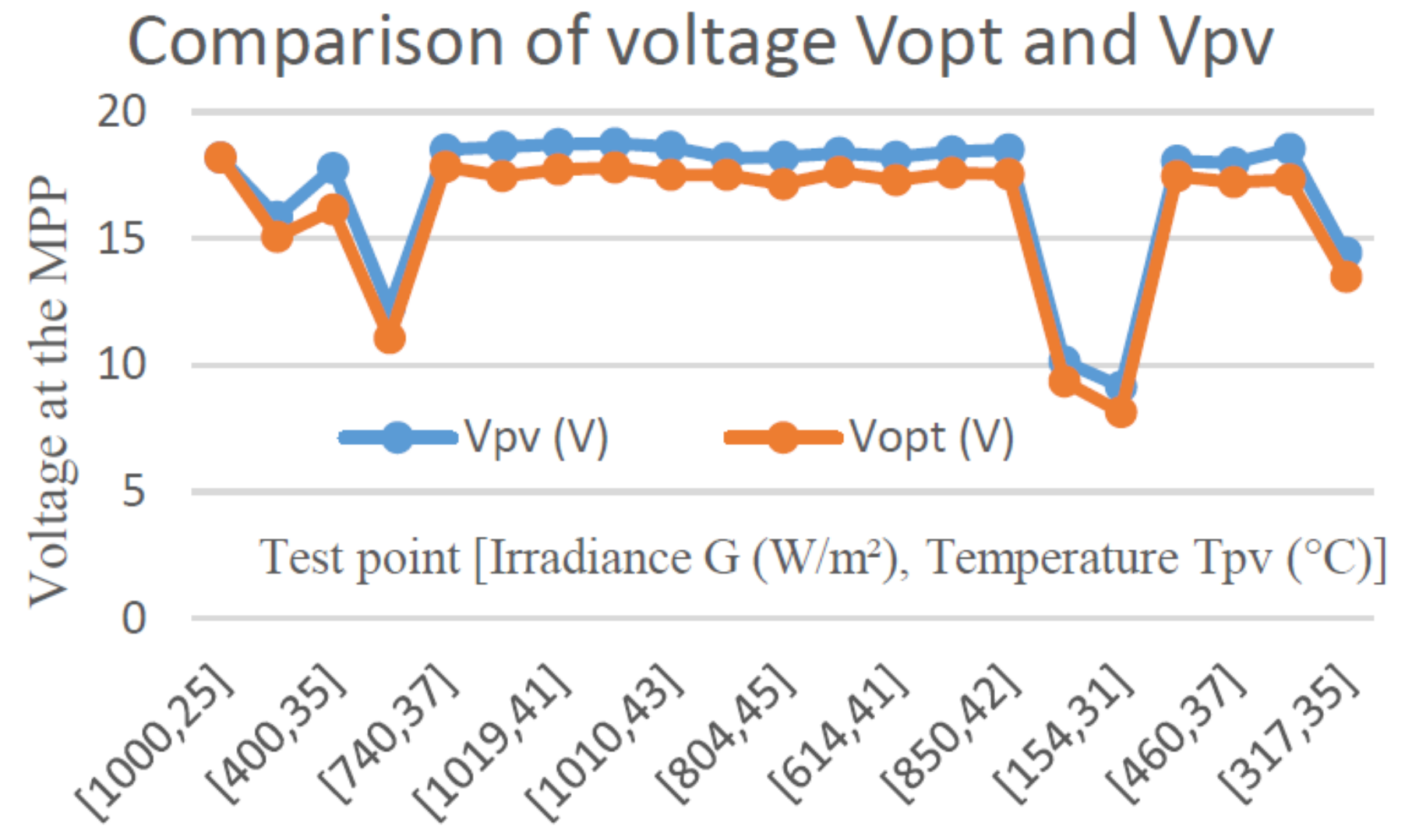

Figure 17

comparison between neural output of neural voltage and Vpv.

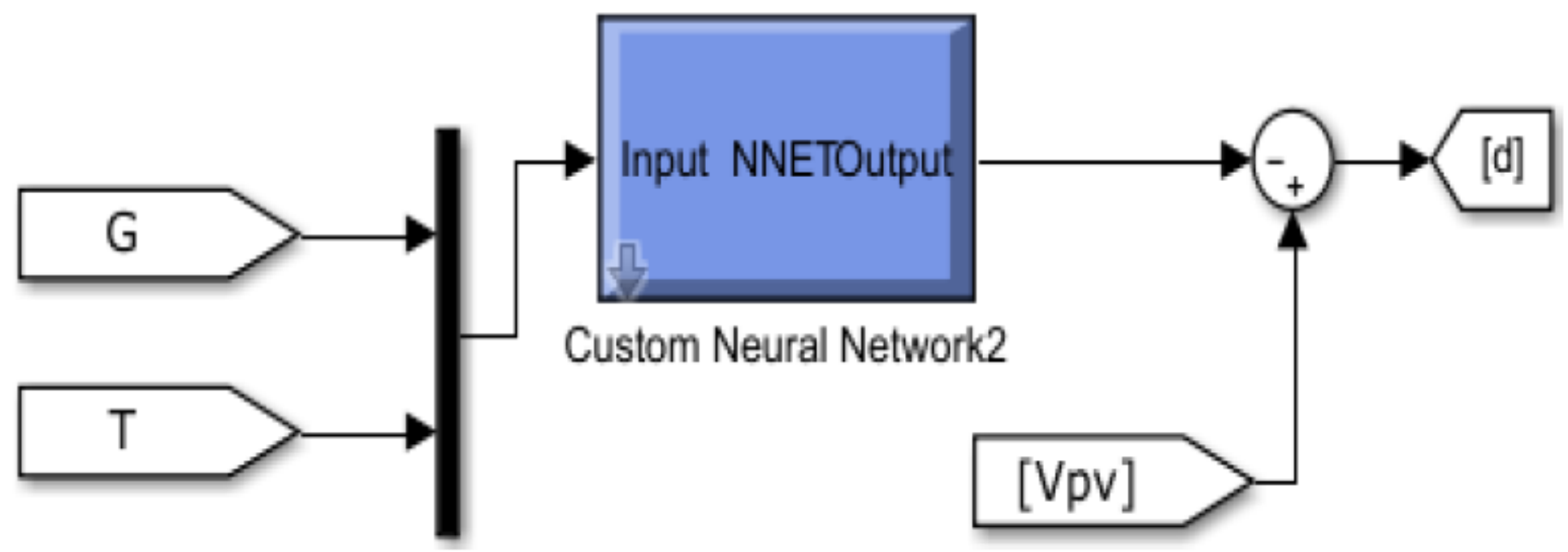

Figure 18 


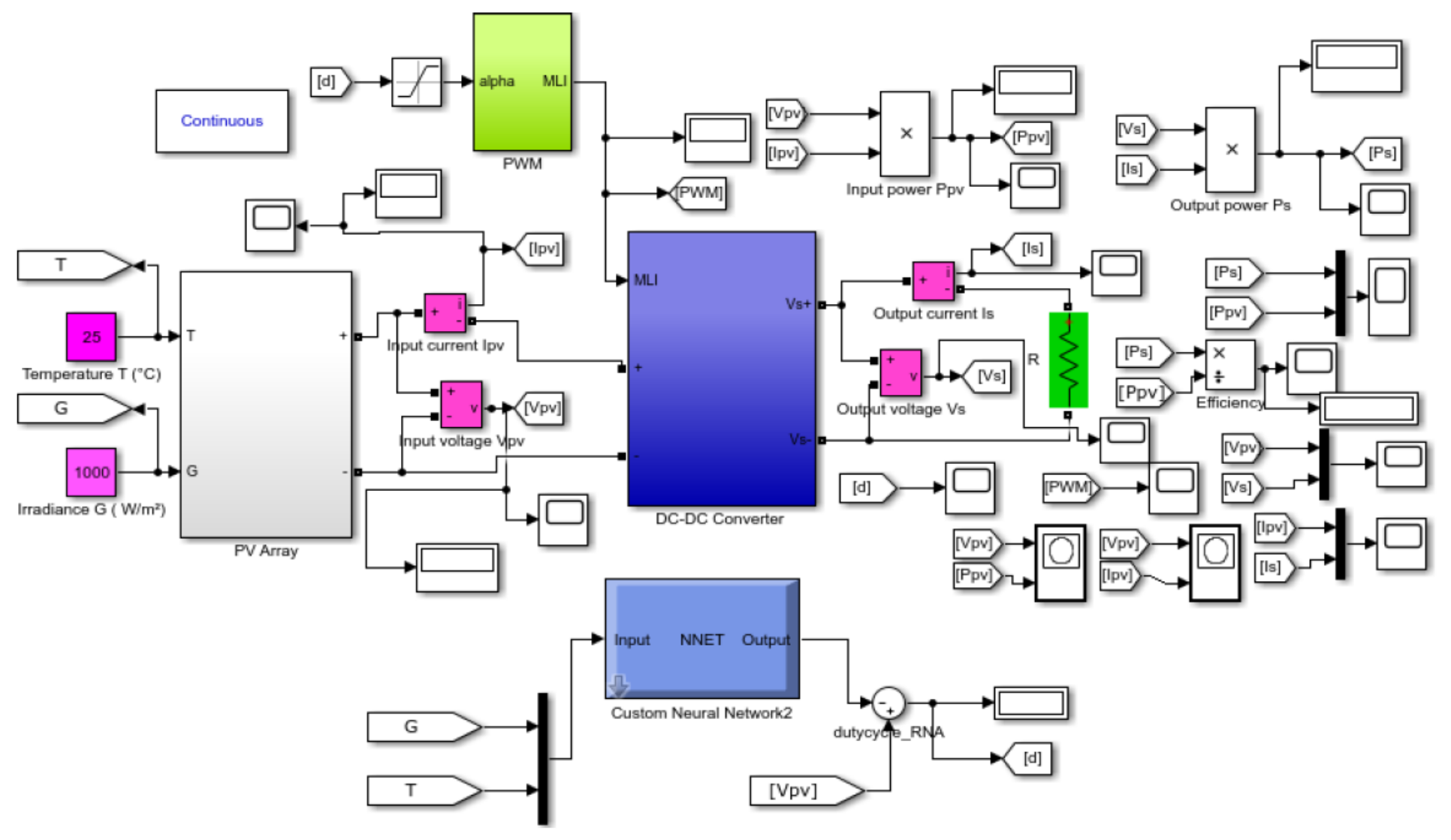

Figure 19

PV system with neural MPPT controller 


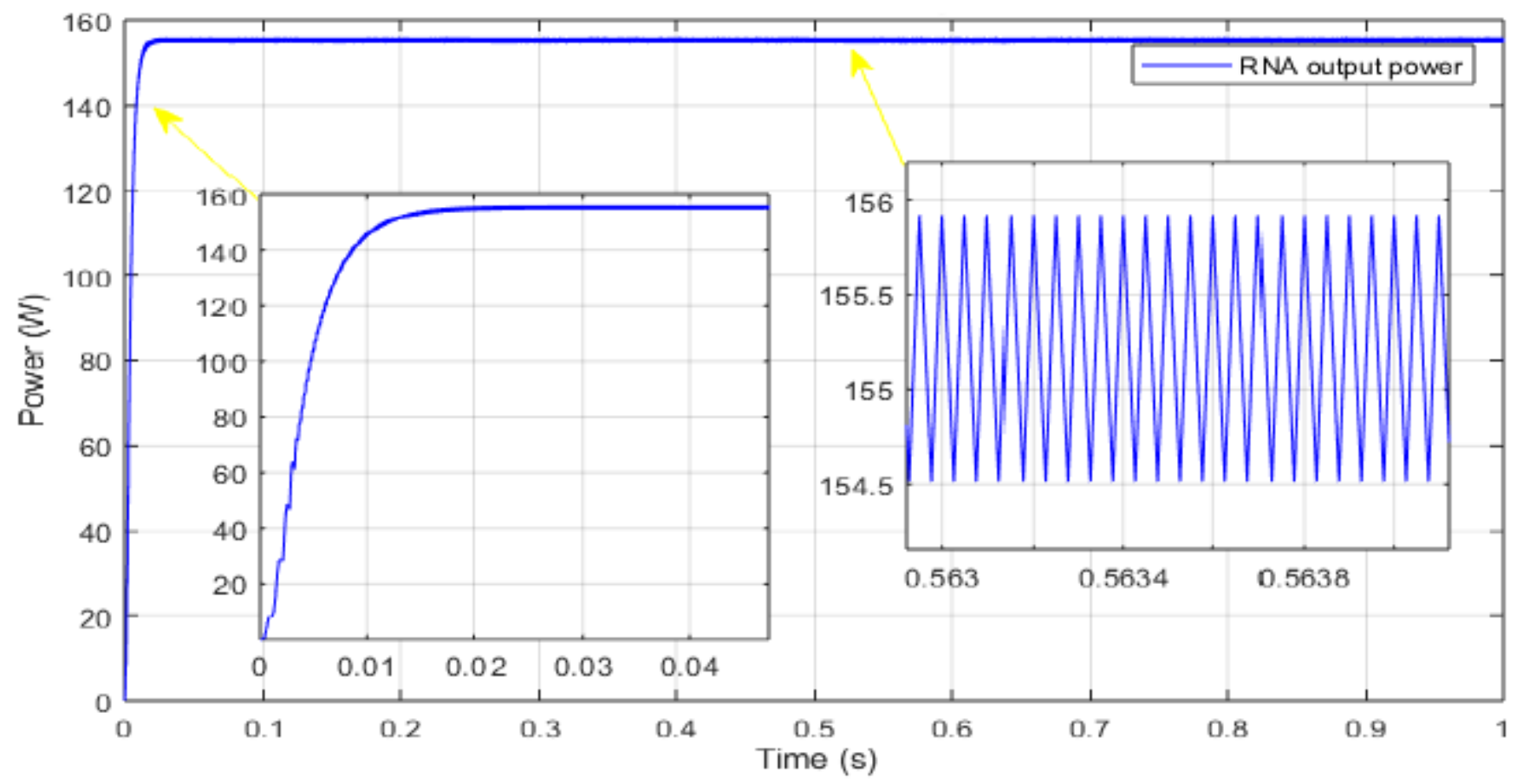

Figure 20

Panel output power

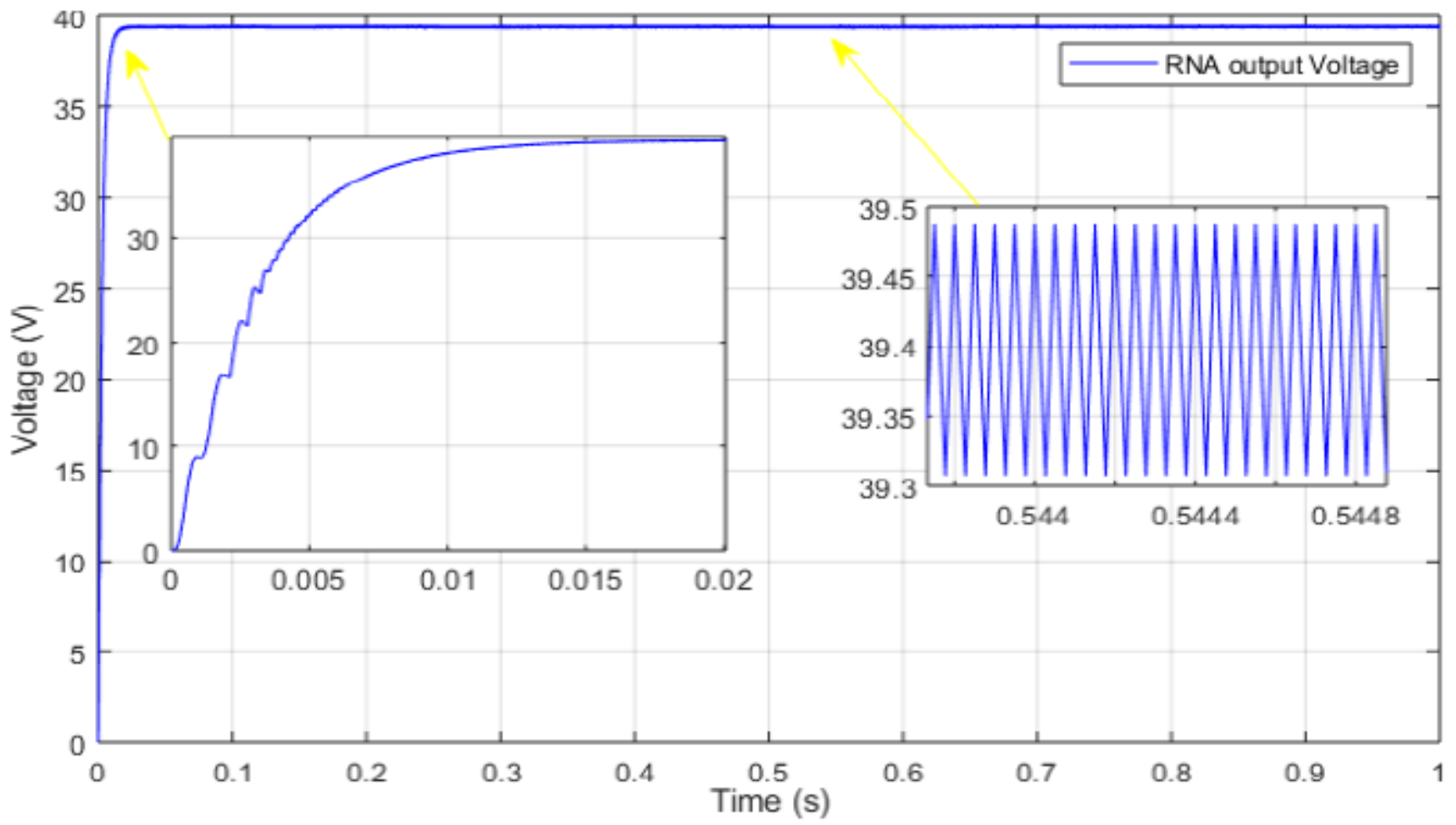

Figure 21 
Panel output voltage

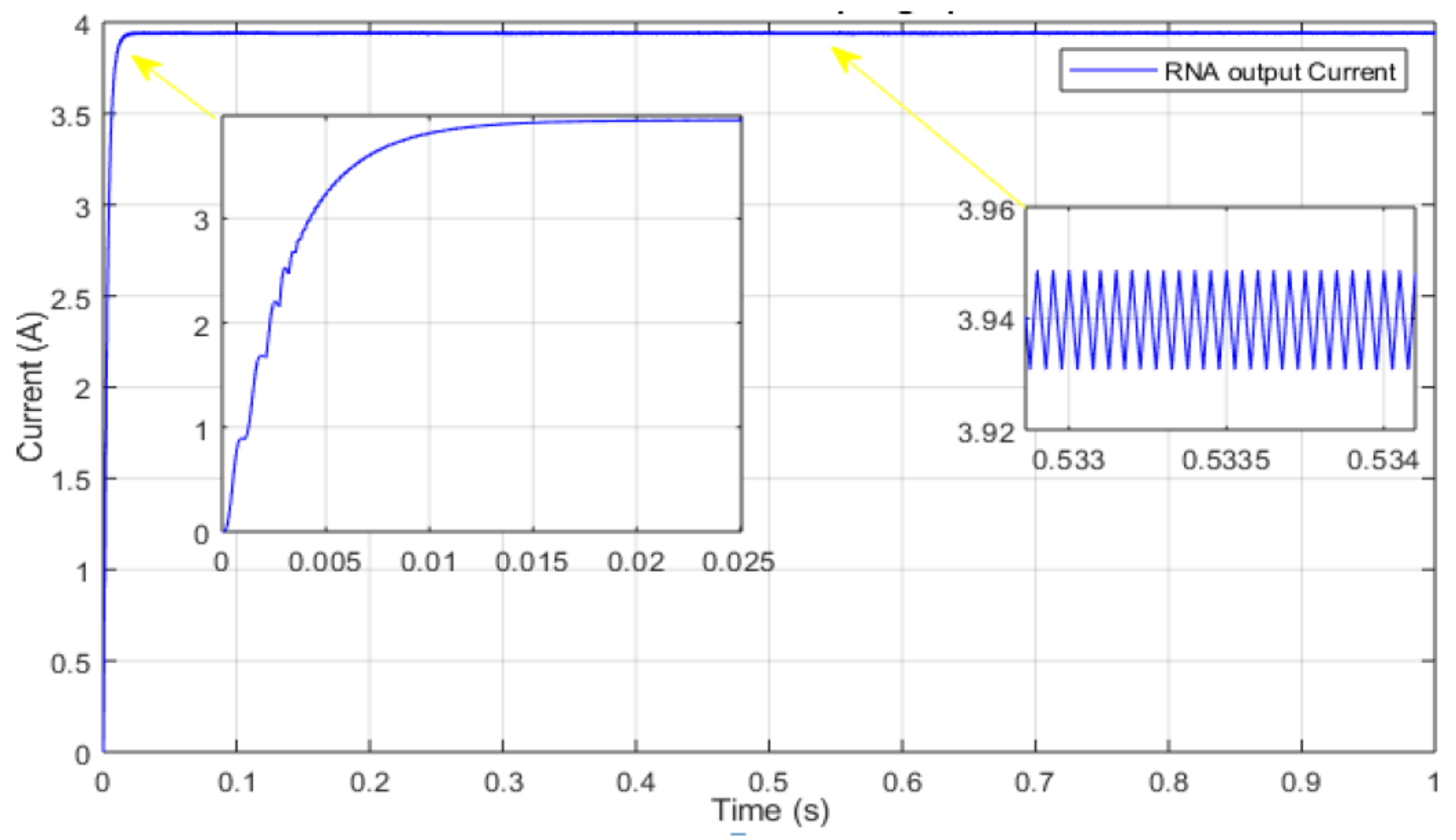

Figure 22

Panel output current 


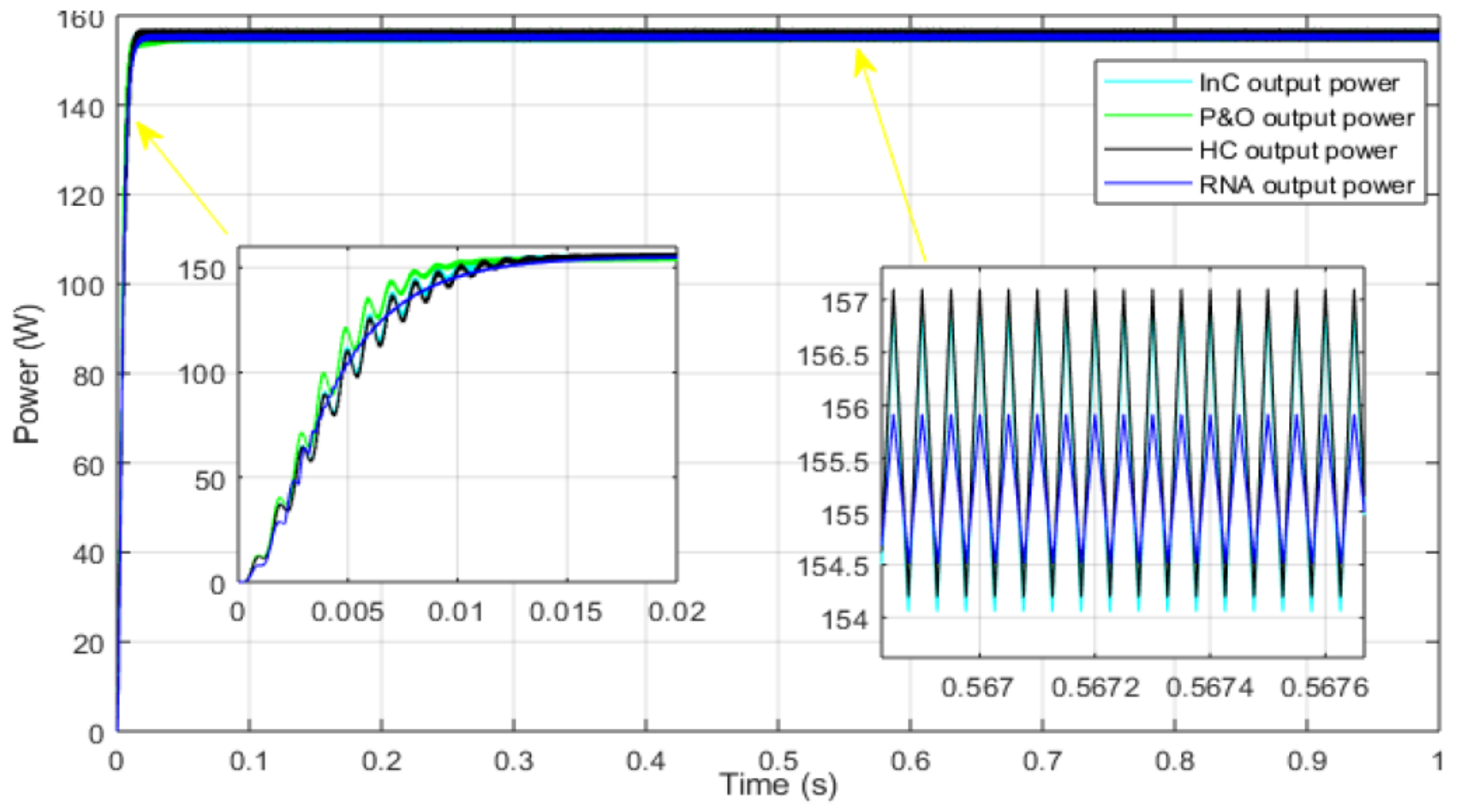

Figure 23

Power output for various MPPT control in steady state

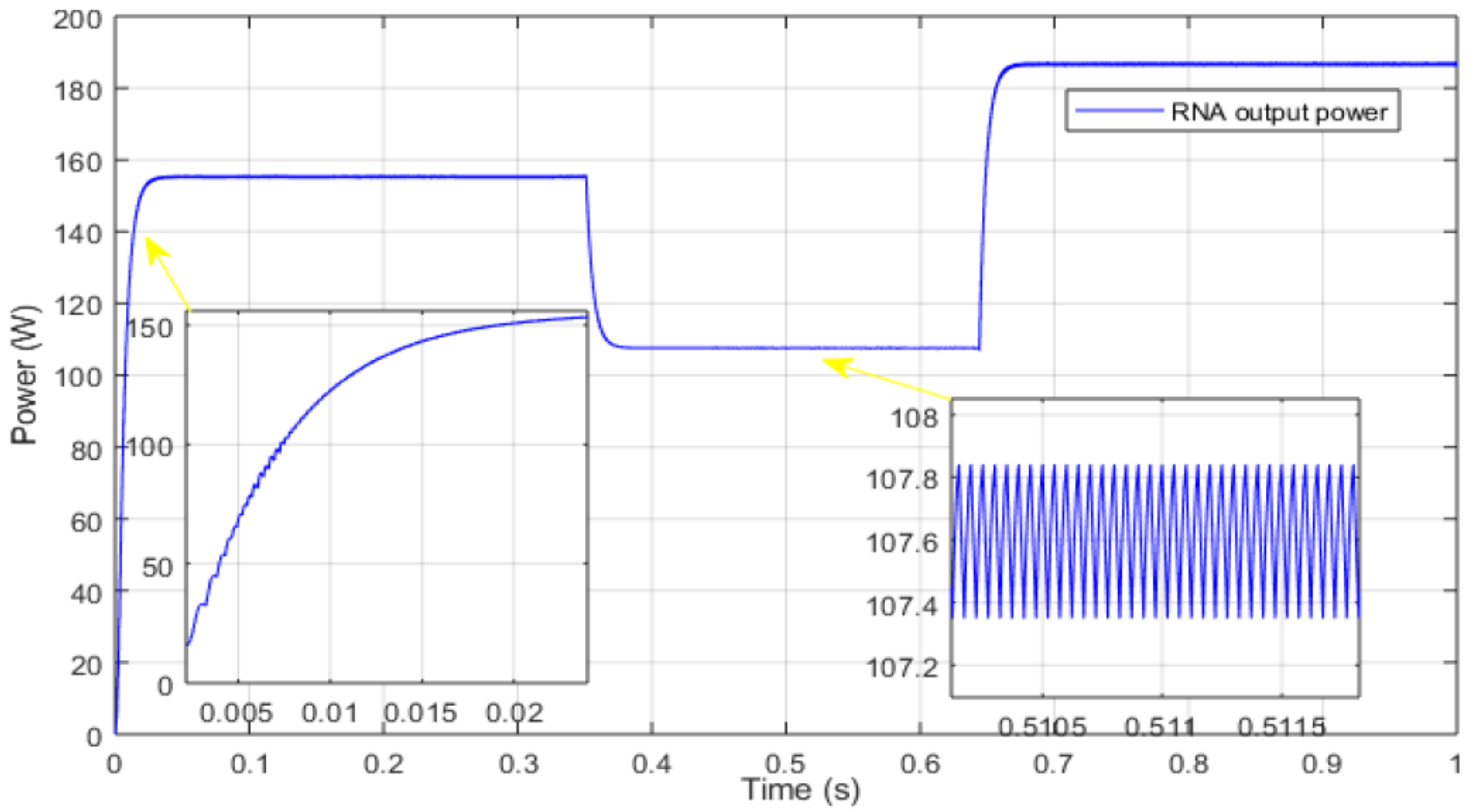


Figure 24

Disturbed output power

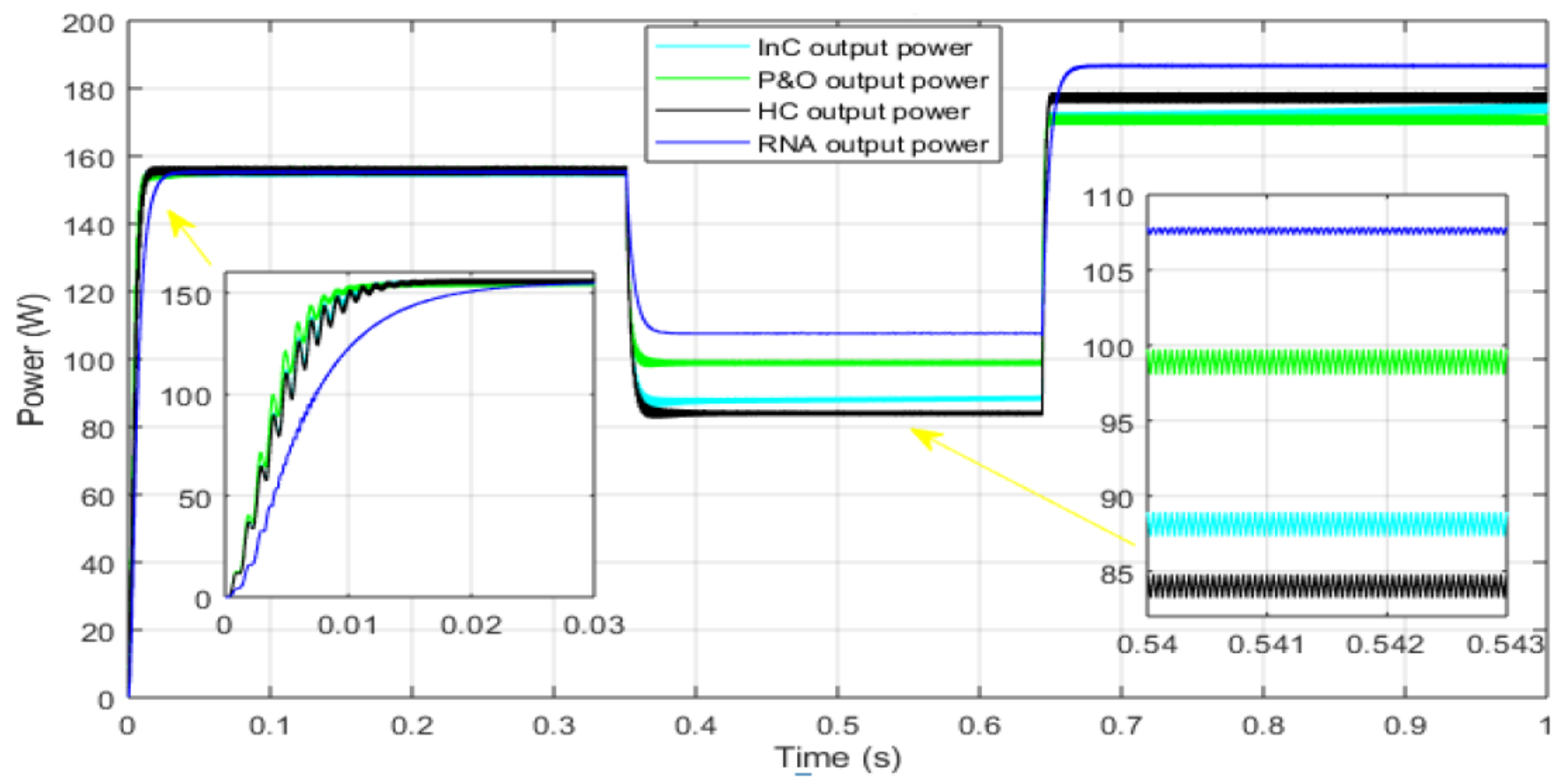

Figure 25

Comparison of output powers in unstable conditions 


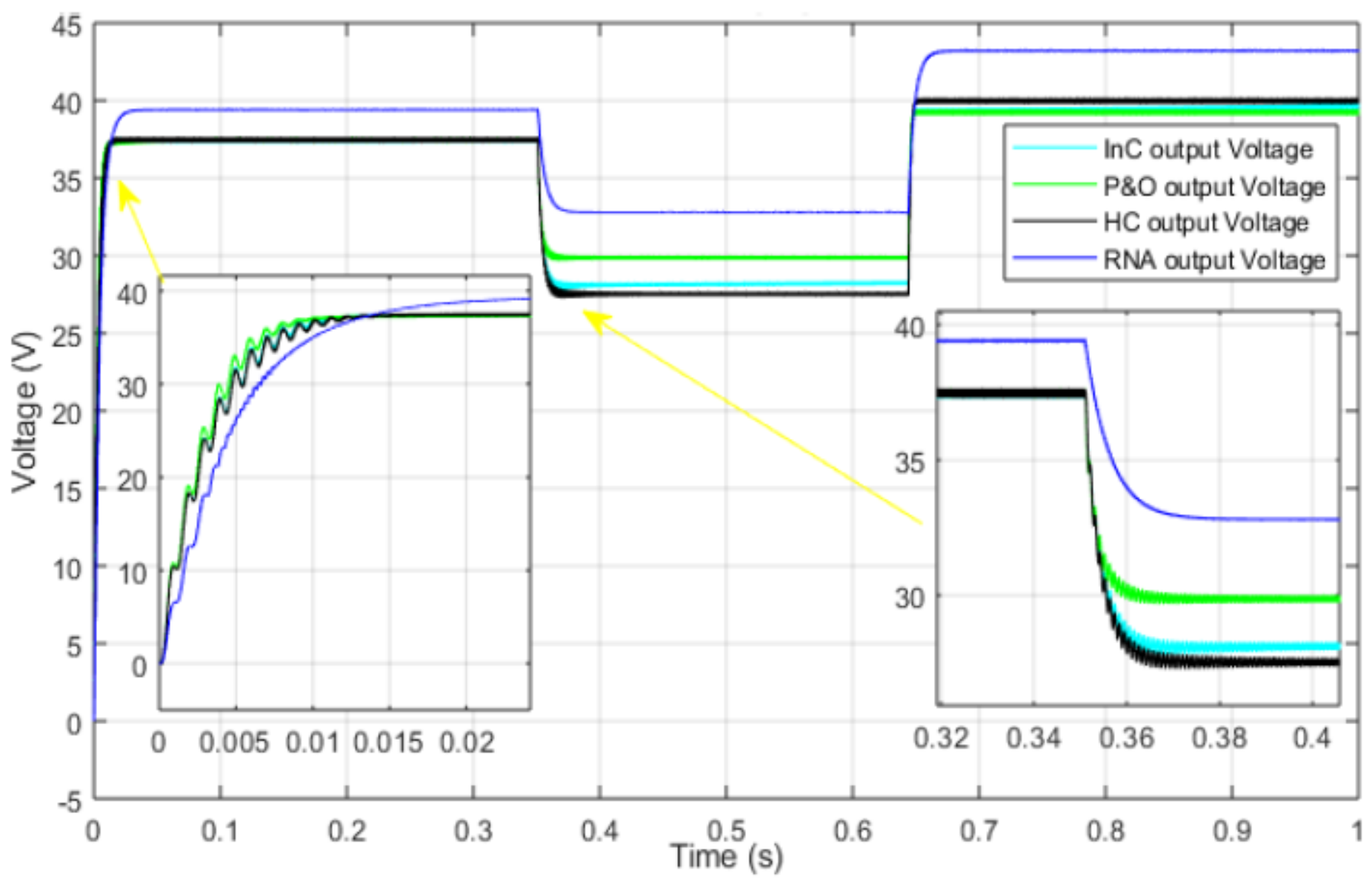

Figure 26

Comparison of output voltages in unstable conditions 


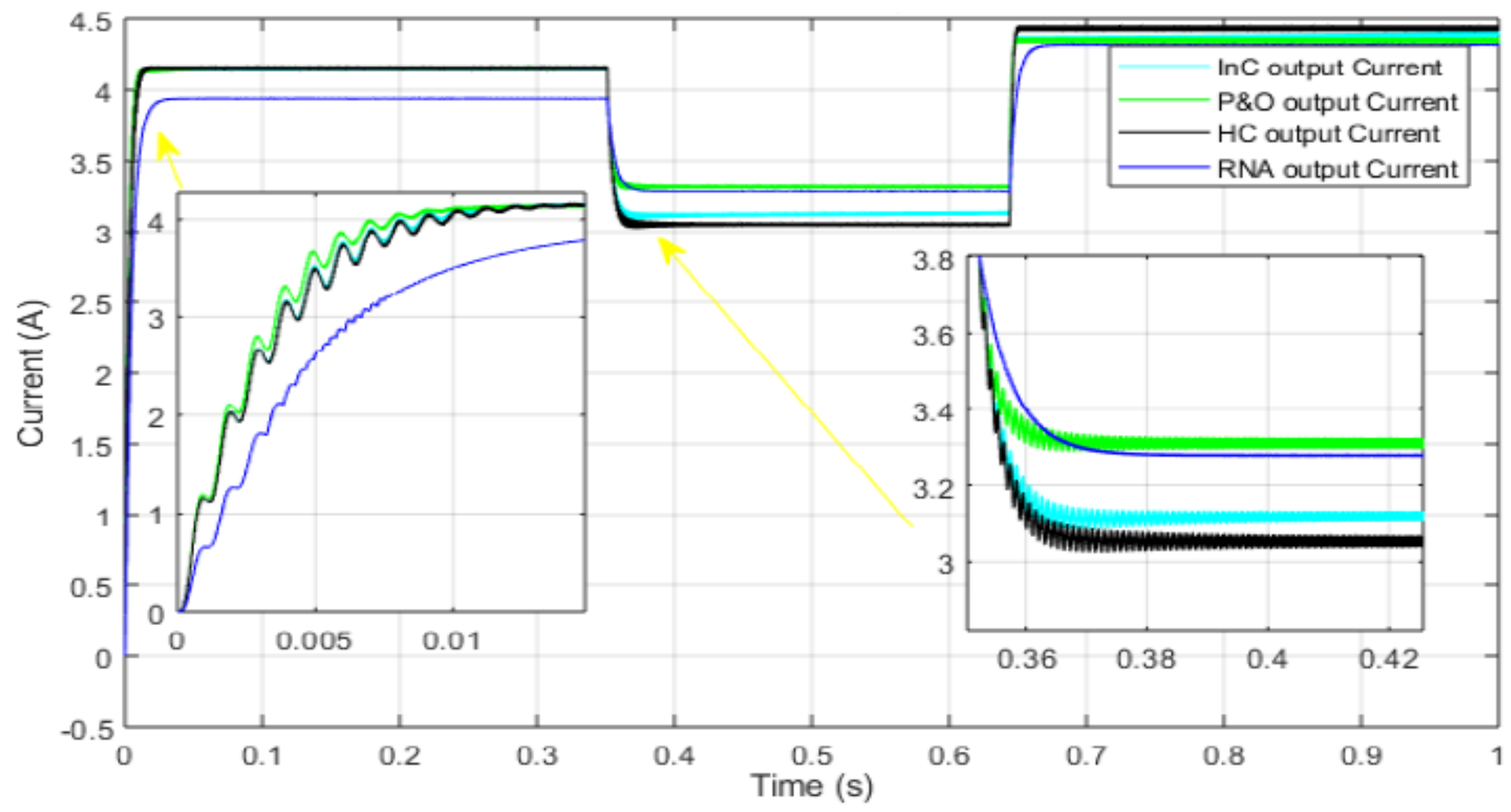

Figure 27

Comparison of output currents in unstable conditions 